\title{
Technologies for Pre-screening IAEA Swipe Samples
}

Final Report - FY15

Nuclear Engineering Division 


\begin{abstract}
About Argonne National Laboratory
Argonne is a U.S. Department of Energy laboratory managed by UChicago Argonne, LLC under contract DE-AC02-06CH11357. The Laboratory's main facility is outside Chicago, at 9700 South Cass Avenue, Argonne, Illinois 60439. For information about Argonne and its pioneering science and technology programs, see www.anl.gov.
\end{abstract}

\title{
DOCUMENT AVAILABILITY
}

Online Access: U.S. Department of Energy (DOE) reports produced after 1991 and a growing number of pre-1991 documents are available free via DOE's Sci Tech Connect (http://www.osti.gov/scitech/).

Reports not in digital format may be purchased by the public from the National Technical Information Service (NTIS):

U.S. Department of Commerce

National Technical Information Service

5301 Shawnee Road

Alexandria, VA 22312

unw.ntis.gov

Phone: (800) 553-NTIS (6847) or (703) 605-6000

Fax: (703) 605-6900

Email: orders@ntis.gov

Reports not in digital format are available to DOE and DOE contractors from the Office of Scientific and Technical Information (OST):

U.S. Department of Energy

Office of Scientific and Technical Information

P.O. Box 62

Oak Ridge, TN 37831-0062

unw.osti.gov

Phone: (865) 576-8401

Fax: (865) 576-5728

Email: reports@osti.gov

\section{Disclaimer}

This report was prepared as an account of work sponsored by an agency of the United States Government. Neither the United States Government nor any agency thereof, nor UChicago Argonne, LLC, nor any of their employees or officers, makes any warranty, express or implied, or assumes any legal liability or responsibility for the accuracy, completeness, or usefulness of any information, apparatus, product, or process disclosed, or represents that its use would not infringe privately owned rights. Reference herein to any specific commercial product, process, or service by trade name, trademark, manufacturer, or otherwise, does not necessarily constitute or imply its endorsement, recommendation, or favoring by the United States Government or any agency thereof. The views and opinions of document authors expressed herein do not necessarily state or reflect those of the United States Government or any agency thereof, Argonne National Laboratory, or UChicago Argonne, LLC. 


\section{Technologies for Pre-screening IAEA Swipe Samples}

\section{Final Report - FY15}

Prepared by

Jennifer L. Steeb, Nicholas A. Smith

Nuclear Engineering Division, Argonne National Laboratory

Denise L. Lee, Heath A. Huckabay

Nuclear Security and Isotope Technology Division, Oak Ridge National Laboratory

Brian W. Ticknor

Chemical Sciences Division, Oak Ridge National Laboratory

November 9, 2015 



\section{EXECUTIVE SUMMARY}

During the course of International Atomic Energy Agency (IAEA) inspections, many samples are taken for the purpose of verifying the declared facility activities and identifying any possible undeclared activities. One of these sampling techniques is the environmental swipe sample. Due to the large number of samples collected, and the amount of time that is required to analyze them, prioritizing these swipes in the field or upon receipt at the Network of Analytical Laboratories (NWAL) will allow sensitive or mission-critical analyses to be performed sooner.

As a result of this study, technologies were placed into one of three categories: recommended, promising, or not recommended. Both neutron activation analysis (NAA) and X-ray fluorescence (XRF) are recommended for further study and possible field deployment. These techniques performed the best in initial trials for pre-screening and prioritizing IAEA swipes. We learned that for NAA more characterization of cold elements (such as calcium and magnesium) would need to be emphasized, and for XRF it may be appropriate to move towards a benchtop XRF versus a handheld XRF due to the increased range of elements available on benchtop equipment. Promising techniques that will require additional research and development include confocal Raman microscopy, fluorescence microscopy, and infrared (IR) microscopy. These techniques showed substantive responses to uranium compounds, but expensive instrumentation upgrades (confocal Raman) or university engagement (fluorescence microscopy) may be necessary to investigate the utility of the techniques completely. Pointand-shoot (handheld) Raman and attenuated total reflectance-infrared (ATR-IR) measurements are not recommended, as they have not shown enough promise to continue investigations. 


\section{CONTENTS}

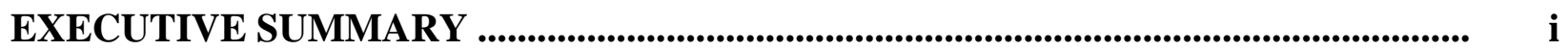

ACKNOWLEDGMENTS ........................................................................................... vi

ACRONYMS AND INITIALISMS .......................................................................................... vii

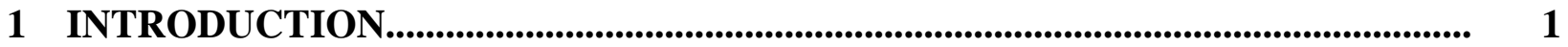

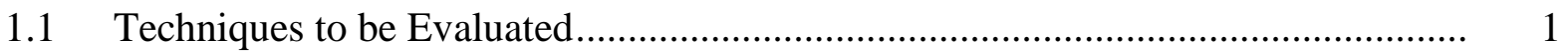

1.2 Experimental Plan ..........................................................................................

2 BACKGROUND INFORMATION _........................................................................................ 2

2.1 IAEA Environmental Swipe Samples …………………………………………..... 2

2.2 NWAL Analysis ................................................................................................ 2

$2.3 \quad$ X-Ray Fluorescence .............................................................................................

2.4 Neutron Activation Analysis ............................................................................... 5

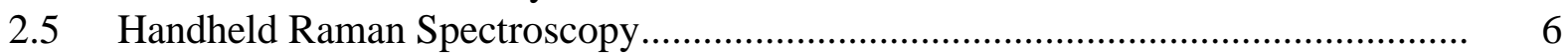

2.6 Confocal Raman Microscopy ................................................................................ 7

$2.7 \quad$ Fluorescence Microscopy ..................................................................................... 8

$2.8 \quad$ ATR Infrared Spectroscopy ............................................................................

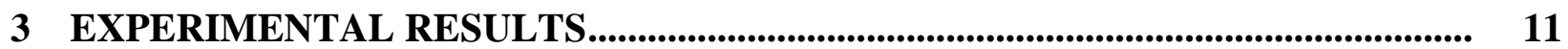

3.1 Simulated IAEA Swipe Samples...................................................................... 11

3.2 NWAL Analysis ........................................................................................ 12

3.2.1 Uranium Content............................................................................... 14

3.2.2 Isotopic Analysis....................................................................... 16

3.3 X-Ray Fluorescence ................................................................................ 18

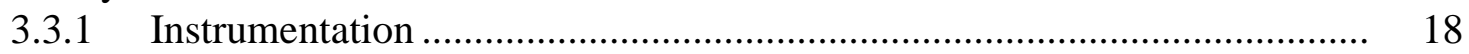

3.3.2 Analysis Methodology ......................................................................... 18

3.3.3 Analysis of Particulates....................................................................... 19

3.3.4 Initial Testing with Cobalt .............................................................. 19

3.3.5 Oak Ridge Standard Swipes............................................................... 21

3.3.6 Uranium and Plutonium Standards …………...................................... 22

3.3.7 Decontamination Swipes ................................................................ 22

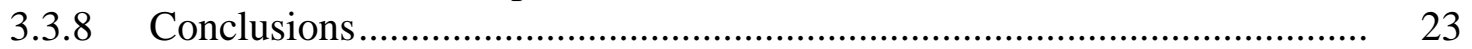

$3.4 \quad$ Neutron Activation Analysis ............................................................................. 23

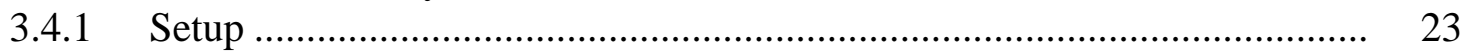

3.4.2 NAA Sensitivity Analysis.............................................................. 24

3.4.3 Fluence Analysis ............................................................................... 25

3.4.4 Depleted Uranium Detectability Analysis .............................................. 25

3.4.5 Magnesium Detectability Analysis ……………………………………... 26 


\section{CONTENTS (CONT.)}

3.4.6 Calcium Detectability Analysis .......................................................... 26

3.4.7 Conclusions ................................................................................... 27

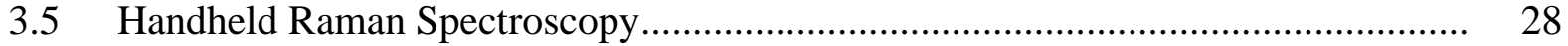

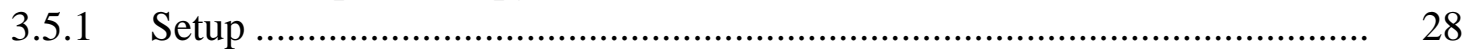

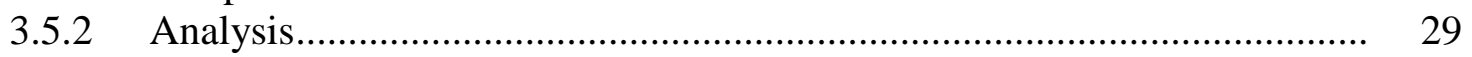

3.6 Confocal Raman Microscopy ...................................................................... 31

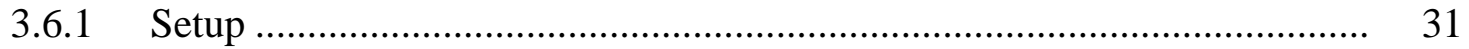

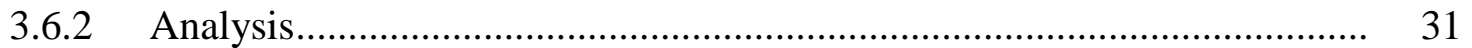

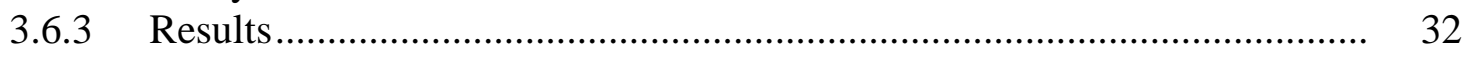

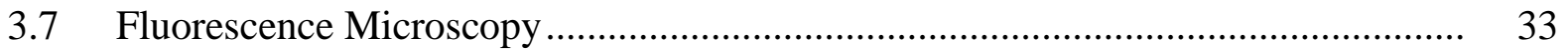

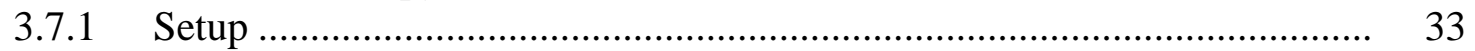

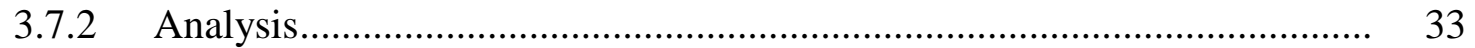

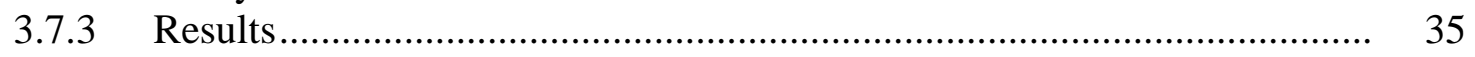

3.8 ATR Infrared Spectroscopy ........................................................................ 36

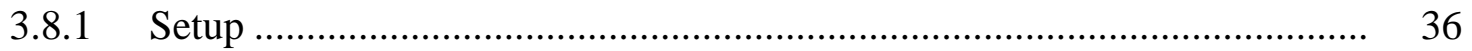

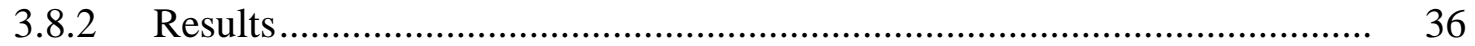

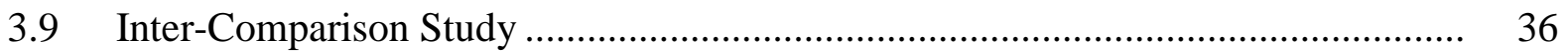

4 SUMMARY AND RECOMMENDATIONS....................................................................... 38

4.1 Recommedned Techniques for Further Research ........................................ 38

4.1.1 XRF.................................................................................... 38

4.1.2 Neutron Activation Analysis.............................................................. 39

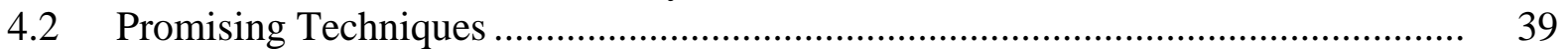

4.2.1 Confocal Raman Microscopy …................................................... 39

4.2.2 Fluorescence Microscopy ................................................................... 40

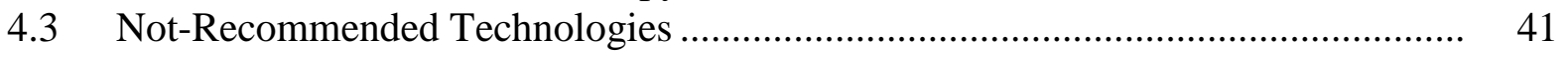

4.3.1 Handheld Raman Analyses ................................................................ 41

4.3.2 ATR Infrared Spectroscopy ................................................................ 41

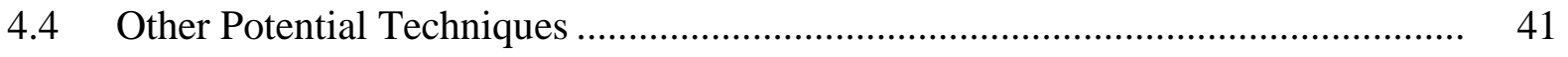

4.4.1 Infrared Micro-Spectroscopy ...................................................... 41

4.4.2 Nuclear Magnetic Resonance ....................................................... 42

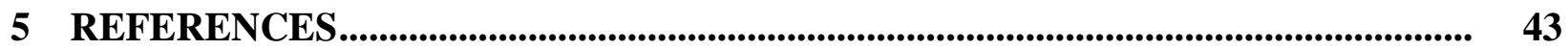




\section{FIGURES}

1 Principles of XRF.

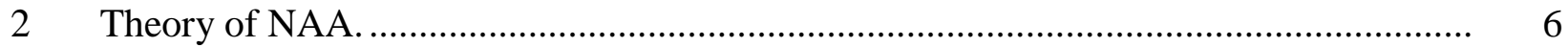

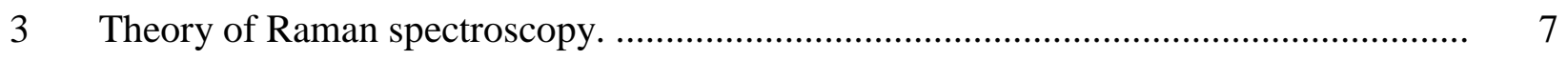

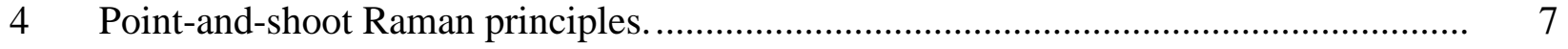

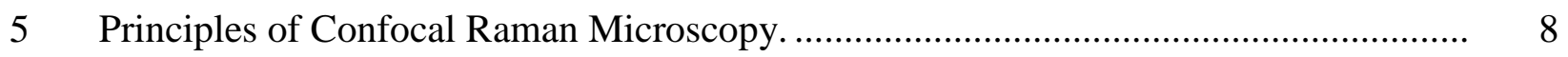

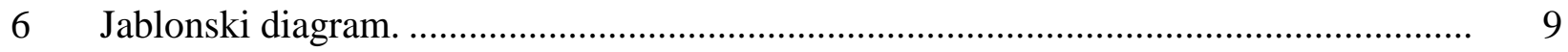

$7 \quad$ Ashed Argonne samples. ................................................................................ 13

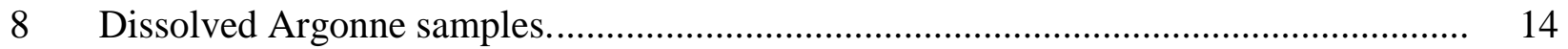

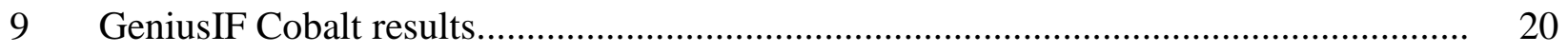

10 Comparison of handheld and benchtop XRFs............................................... 20

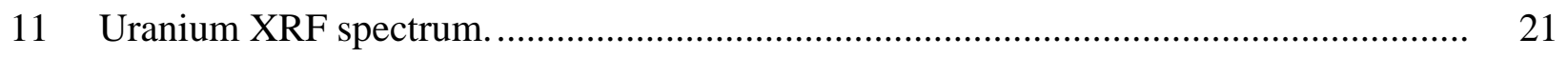

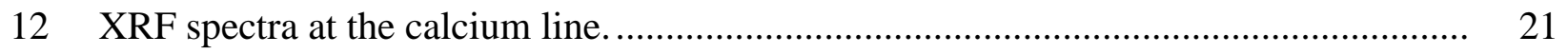

13 XRF results from decontamination swipes.................................................... 23

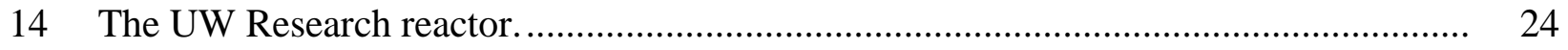

15 HPGe spectrometer counting configuration at UW ........................................... 26

16 Delayed gamma ray spectroscopy for uranium samples....................................... 27

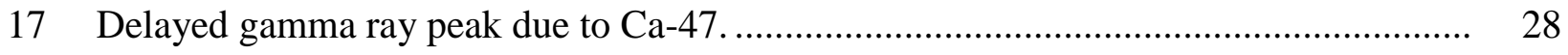

18 Raman scattering. Image obtained using 532-nm excitation................................... 29

19 Raman spectrum of uranyl nitrate ................................................................ 30

$20 \quad$ Raman spectra of uranyl nitrate swipe ............................................................. 32

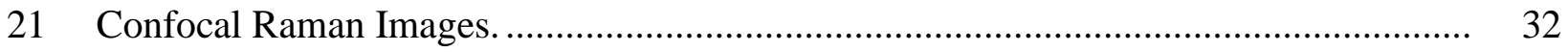




\section{FIGURES (CONT.)}

22 Uranyl fluoride swipe imaged using brightfield and fluorescence microscopy.

23 Lithium hydroxide-doped swipe imaged using brightfield and fluorescence microscopy.

\section{TABLES}

1 Estimated NAA Detection limits using decay gamma rays................................... 5

2 Raman active bands of safeguards-relevant species. ............................................ 8

3 Composition of inter-comparison swipes. ...................................................... 11

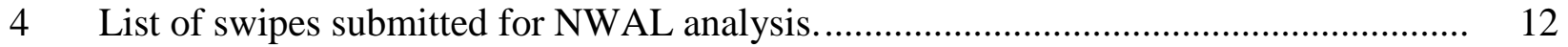

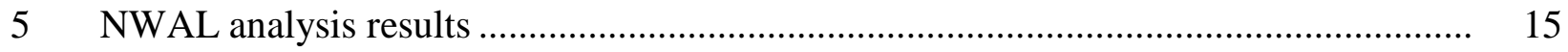

6 Results from analysis of sub-millimeter $\mathrm{KCl}$ particulates by handheld $\mathrm{XRF}$................ 19

$7 \quad$ Composition of $\mathrm{U} / \mathrm{Pu}$ standards and handheld XRF results. .................................. 22

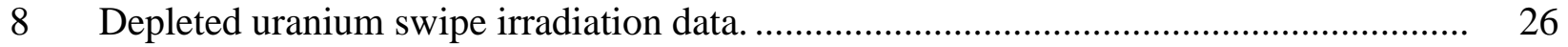

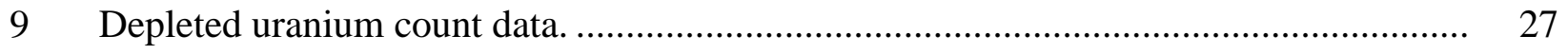

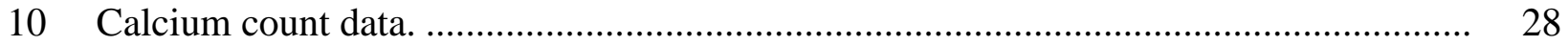

11 Peaks observed in uranyl nitrate Raman spectrum. .......................................... 30

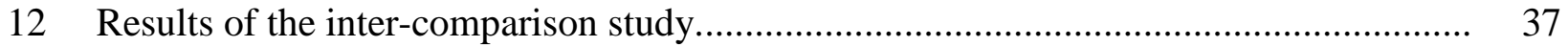




\section{ACKNOWLEDGMENTS}

The authors thank the following individuals for their support during this project:

- Reactor director Bob Agasie, reactor supervisor Corey Edwards, and reactor operators Andrew Maile and Alex (AJ) Gross at the UWNR for their assistance with NAA.

- Richard Wilson at Argonne National Laboratory for confocal Raman spectroscopy assistance and access to the InVia Raman microscope.

- John Krebs at Argonne National Laboratory for assistance and access to the Xenemetrix XRF instrument.

- Debra Bostick, Kayron Tevepaugh, and Eddy McBay at Oak Ridge National Laboratory for the processing and measurement of the samples through the NWAL laboratory.

- Khris Olsen at Pacific Northwest National Laboratory and Brian Gruendell at Pacific Northwest National Laboratory Sequim Marine Research Operations for providing a package of the characterized blank swipes and the plastic bags used in this study. 


\section{ACRONYMS AND INITIALISMS}

\begin{tabular}{|c|c|}
\hline $\begin{array}{l}\text { ANL } \\
\text { ATR }\end{array}$ & $\begin{array}{l}\text { Argonne National Laboratory } \\
\text { attenuated total reflectance }\end{array}$ \\
\hline CIMS & Chemical and Isotopic Mass Spectrometry [lab] \\
\hline DU & depleted uranium \\
\hline HPGe & high-purity germanium [spectrometer] \\
\hline $\begin{array}{l}\text { IAEA } \\
\text { IR }\end{array}$ & $\begin{array}{l}\text { International Atomic Energy Agency } \\
\text { infrared }\end{array}$ \\
\hline MC-ICPMS & multicollector-inductively coupled plasma mass spectrometry \\
\hline $\begin{array}{l}\text { NAA } \\
\text { NMR } \\
\text { NWAL }\end{array}$ & $\begin{array}{l}\text { neutron activation analysis } \\
\text { nuclear magnetic resonance } \\
\text { Network of Analytical Laboratories }\end{array}$ \\
\hline ORNL & Oak Ridge National Laboratory \\
\hline PNNL & Pacific Northwest National Laboratory \\
\hline TBP & tributyl phosphate \\
\hline $\begin{array}{l}\text { UW } \\
\text { UWNR }\end{array}$ & $\begin{array}{l}\text { University of Wisconsin-Madison } \\
\text { University of Wisconsin Nuclear Reactor }\end{array}$ \\
\hline XRF & X-ray fluorescence \\
\hline
\end{tabular}




\section{INTRODUCTION}

During the course of International Atomic Energy Agency (IAEA) inspections, many samples are taken for the purpose of verifying the declared facility activities, as well as identifying any possible undeclared activities. One of these sampling techniques is the environmental swipe sample. These swipes are collected from various locations around a site and sent for analysis, primarily at designated facilities that are part of the Network of Analytical Laboratories (NWAL).

Due to the large number of samples collected, and the amount of time required to analyze them, prioritizing these swipes in the field or upon receipt at NWAL will allow sensitive or mission-critical analyses to be performed sooner. This information can then be used to indicate additional tests, perhaps even while IAEA personnel are still on-site or nearby. To achieve this goal, this study reviewed and tested technologies that can provide rapid assays of the swipe content, either in the field or at NWAL. The pre-screening assays should be able to detect items of safeguards significance, such as fluoride compounds (enrichment operations); tributyl phosphate (TBP), aliphatic liquids, or nitric acid (reprocessing); $\mathrm{Ca}$ or other alkaline metals (metal production); or simply the presence of actinides (special nuclear materials).

\subsection{TECHNIQUES TO BE EVALUATED}

A technology review was initially conducted by staff from Argonne and Oak Ridge national laboratories and presented in Argonne report ANL/NE-15/5 (Steeb 2015). This review identified six potential technologies that could identify portions of the previously mentioned safeguards signals; none of the surveyed techniques could provide all of the information. Due to the non-radiological nature of the bulk of the targets, and as passive radiological detection techniques have been well vetted by other projects and offices, chemical analysis and active interrogation techniques were given priority. Techniques evaluated at Oak Ridge were lowintensity neutron activation analysis (NAA), fluorescence microscopy, and handheld Raman spectroscopy. Techniques evaluated at Argonne were X-ray fluorescence (XRF) spectroscopy, confocal Raman spectroscopy, and attenuated total reflectance-infrared (ATR-IR) spectroscopy.

\subsection{EXPERIMENTAL PLAN}

Each technique was evaluated on an individual basis by the team members at their respective laboratories to determine optimal parameters and initial responses. Those techniques that showed promise were tested further to establish the rough limits of operation and any interferences (if known). Finally, the techniques were compared by analyzing a series of swipes prepared by Oak Ridge. These swipes were then analyzed by the Oak Ridge NWAL to confirm the concentration of material on the samples. This round-robin testing established the minimum requirements for identifying the components of the target compound. 


\section{BACKGROUND INFORMATION}

This section provides the relevant background information on each technique, as well as its potential safeguards application or use. In addition, the methodology for preparing and collecting swipe samples by the IAEA and their analysis by NWAL is described.

\subsection{IAEA ENVIRONMENTAL SWIPE SAMPLES}

The IAEA currently fields two different swipe sampling kits: one kit is composed of multiple square $100-\mathrm{cm}^{2}$ cotton cloths for general facility sampling, while the other kit is designed specifically for use in hot cell environments (Kuhn 2001). The general cotton swipes come in a pre-packaged kit and are used by trained inspectors according to facility-specific sampling plans. The materials have been specifically chosen for their ease of use and analysis. The hot cell sampling kit is designed for higher-activity materials and comes with multiple layers of containment, including a lead shield for transport. The actual swipe material in these kits is a round cellulose-based swipe that is packaged in a poly bottle, a lead shield, and an aluminum transport container.

While both types of swipes are routinely used, this study focused on the cotton swipes. This is due to the number and characteristics of the expected materials on each type of sample. Materials may or may not be expected on the cotton swipes, meaning that the analytical emphasis will tend toward lower limits of detection and broad sensitivity. In addition, more cotton samples are generally taken at more facilities, as not every facility has hot cells that are monitored (e.g., an enrichment facility). Hot cell samples, when taken, would generally be assumed to have a higher level of material on them. Therefore, the analytical requirements shift from determining if material is present to analyzing the characteristics of the material that is present.

\subsection{NWAL ANALYSIS}

The purpose of the NWAL analysis for the project is two-fold. First, the goal is to verify that the material loaded (U or otherwise) is compatible with the standard NWAL chemistry. This is especially true in the cases of swipes loaded with high levels of $\mathrm{Ca}$ or Li. These elements are not typically found in high abundance in samples of this type, and their presence could negatively impact either the separation chemistry or the mass spectrometric analysis. Because the swipes have a well-characterized $\mathrm{U}$ content, deviations from the expected $\mathrm{U}$ isotopics or quantities will indicate a problem with the NWAL procedure to handle that sample. This would then have implications for the use of that particular indicator in a pre-screening method intended to prioritize samples for more prompt NWAL analysis.

The second goal of the full NWAL analysis is to verify that any of the screening methods employed, as well as the cross-country transport of the samples, do not create any kind of contamination or change to the $\mathrm{U}$ content of the swipe, which is one of the basic requirements for 
the eventual implementation of any pre-screening technique. This is especially relevant in the activation analysis at the reactor or with any analysis using a laser that may have the potential to puncture the plastic bags in which a swipe is contained.

Oak Ridge National Laboratory was one of the original participating labs when the IAEA began the environmental sampling program in the mid-1990s. Currently, the Chemical and Isotopic Mass Spectrometry (CIMS) lab at Oak Ridge is one of four domestic IAEA-qualified NWAL that supports the Bulk Analysis of Environmental Samples Program at the IAEA. As such, the CIMS lab has specialized procedures and clean room facilities in place to handle the dissolution, purification, and analysis of swipe samples.

The Oak Ridge procedure is designed to concentrate and purify $\mathrm{U}$ and $\mathrm{Pu}$ from bulk environmental samples for subsequent analysis using multicollector-inductively coupled plasma mass spectrometry (MC-ICPMS). If samples are submitted as cotton or paper swipes, they are ashed at $600{ }^{\circ} \mathrm{C}$ to destroy the swipe matrix. The ash residue is dissolved in strong acid (e.g., nitric acid). Plutonium and uranium isotopic spikes are added to an aliquot of the dissolved sample for quantification by isotope dilution mass spectrometry. An unspiked aliquot of the sample is loaded directly onto stacked Eichrom TEVA/UTEVA ${ }^{\circledR}$ columns, from which purified $\mathrm{Pu}$ and $\mathrm{U}$ fractions are eluted and the isotopic composition determined by MC-ICPMS. An abbreviated version of the CIMS NWAL procedure is listed below:

1. Samples are dry-ashed in leached glass tubes for about 12 hours in a furnace, with a ramped temperature profile reaching $600^{\circ} \mathrm{C}$.

2. After the sample is ashed, the furnace tube containing the ash is transferred to the appropriate clean room laboratory depending on the estimate of its $U$ content. Acid is added gravimetrically to the ash and the sample is heated to ensure complete dissolution.

3. Approximately $1 \%$ of the sample is removed to screen (by ICP-MS) for U quantification and isotope identification, as well as to identify significant amounts of trace element contaminants in the sample. The result of the screen is used to select appropriate aliquot size and spike levels during further processing.

4. Chemical processing of the samples utilizes cleaned, prepared UTEVA columns to purify $\mathrm{U}$ from the remainder of the sample matrix. Typically, up to $60 \%$ of the dissolved sample is purified for $\mathrm{U}$ isotopic analysis, up to $20 \%$ is spiked with ${ }^{233} \mathrm{U}$ tracer and then purified for concentration determination by isotope dilution mass spectrometry, and $20 \%$ is archived for re-analysis if required.

5. The spiked and unspiked $U$ aliquots are then submitted for mass spectrometric analysis. A Thermo Scientific Neptune MC-ICPMS is used to analyze the samples. Typically, the ${ }^{233} \mathrm{U} /{ }^{238} \mathrm{U}$ ratio is monitored in the spiked fraction, while the ${ }^{234} \mathrm{U} /{ }^{238} \mathrm{U},{ }^{235} \mathrm{U} /{ }^{238} \mathrm{U}$, and ${ }^{236} \mathrm{U} /{ }^{238} \mathrm{U}$ ratios are all monitored in the unspiked fraction. The combination of the spiked and unspiked analyses allows the calculation of the $U$ concentration in the sample. 
6. The full combined uncertainty budget in both the reported concentration and isotope ratio measurements is made up of components from both the chemistry (gravimetric dissolution and weighing of spikes) and from the mass spec analysis (calibration of instrument and count rate of the sample).

For the mock samples produced and analyzed for this project, Pu was not added and was thus not purified and measured. Blank swipes, or those loaded with other elements such as Li or $\mathrm{Ca}$, have a natural $\mathrm{U}$ background $(\sim 2.5 \mathrm{ng} \mathrm{U})$ that is inherent to the cotton matrix, and thus these swipes can be analyzed for trace $\mathrm{U}$. The Pu background is essentially non-existent, however, so $\mathrm{Pu}$ analyses were not performed.

\subsection{X-RAY FLUORESCENCE}

The XRF spectrometer is used to determine the chemical composition of a sample via characteristic X-ray emission. In principle, the instrument generates X-rays, which are collimated onto the sample of interest. When the X-ray energy exceeds the ionization energy of an element in the sample, it may eject a core electron. As the vacancy is filled by higher-energy electrons, they emit characteristic (or fluorescent) $\mathrm{X}$-rays, which can then be used to identify the element (Figure 1). Furthermore, the signal intensity of the $\mathrm{X}$-ray is proportional to the concentration of the element in the sample.

The pattern of X-rays that are emitted is distinctive to a particular element,

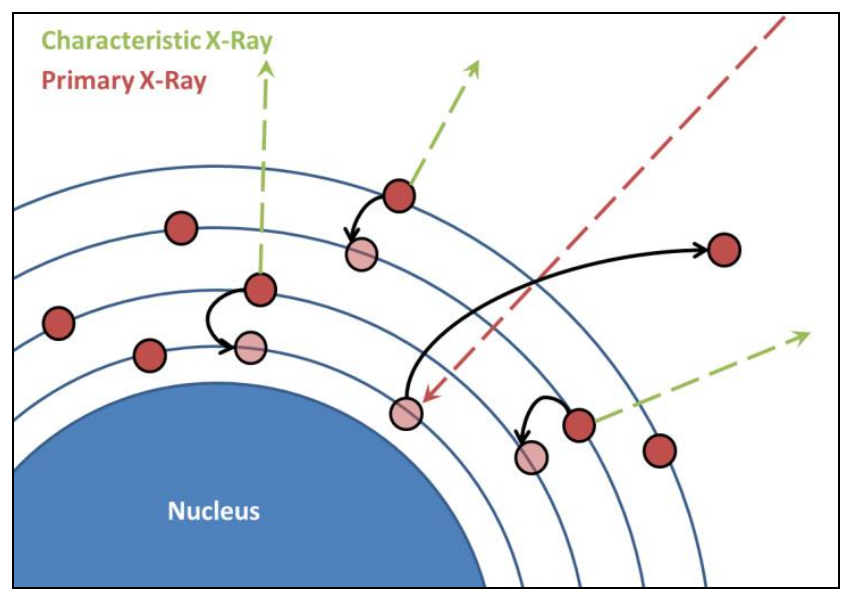

Figure 1-Principles of XRF. As atoms are bombarded by $\mathrm{X}$-rays, core electrons can be ejected, after which higher-energy electrons drop to fill the vacancy. This starts a cascade that generates multiple characteristic $\mathrm{X}$-rays. though there may be similar energy levels in multiple elements. This similarity leads to situations where elements have interfering X-rays, or lines, that must be taken into account. For example, the $\mathrm{L}_{\alpha 1} \mathrm{Br}$ line and the $\mathrm{K}_{\alpha 2} \mathrm{Al}$ line are only $5.84 \mathrm{eV}$ from one another. Using a handheld instrument, this is a separation that could not be resolved easily if the sample contains, or may contain, both elements; benchtop instruments may be able to resolve these peaks, with a concurrent increase in the price of the instrument. However, both $\mathrm{Br}$ and $\mathrm{Al}$ have other lines that can be used for positive identification and quantification. Therefore, use of multiple lines for identification is generally recommended. In addition to interferences, XRF instruments generally have a small aperture; this would require multiple measurements on an environmental swipe sample to measure the entire surface.

The potential safeguards use of an XRF instrument is to identify those samples that contain $\mathrm{U}$ or $\mathrm{Pu}$ (in any chemical form) at the part per million level quickly either upon receipt at an analytical laboratory or at a staging area. This level of radioactive material is consistent with 
the amounts that may be found on environmental swipe samples that could be found with a standard swipe counting instrument if the sample were not encased in a plastic bag. It is important to note that the IAEA already uses a laboratory-based XRF instrument to obtain a quantitative elemental analysis on "cold" swipes using a 4- to 5-hour analysis. Additionally, according to IAEA instructions for safeguards techniques and equipment (IAEA 2011), IAEA inspectors use handheld XRF instruments for analysis of metals, alloys, and samples that cannot be removed. Both of these instruments may have safeguards value.

\subsection{NEUTRON ACTIVATION ANALYSIS}

NAA is a sensitive analytical technique useful for performing both qualitative and quantitative multi-element analysis of major, minor, and trace elements (Table 1). NAA uses the thermal or fast neutrons available from either an accelerator neutron source (e.g., a deuteriumtritium generator) or a nuclear reactor. These neutrons are captured by the elements present in the sample; some of these excited nuclei will then decay, releasing characteristic gamma rays that can be used for identification (Figure 2). For many elements and applications, NAA offers sensitivities that are superior to those attainable by other methods, on the order of parts per billion or better. The length of the irradiation, the length of the cooling period, and the type of neutron spectrum to which the sample is exposed will influence both the type of reactions possible and the resulting detection limits.

Certain elements, where one or more reaction will lead to the same excited daughter nucleus, can cause interferences. In these instances, it may be impossible to separate the two signals, and therefore the target cannot be analyzed. In other cases, the daughters may be too short-lived to be able to be measured after the requisite cooling period; in these cases, multiple irradiate/cool cycles may be performed. The other main drawback is that this analysis may be

Table 1-Estimated NAA Detection limits using decay gamma rays.

\begin{tabular}{|c|c|}
\hline $\begin{array}{c}\text { Sensitivity (pg) } \\
\text { assuming a neutron flux of } \\
1 \times 10^{13} \mathrm{n} \cdot \mathrm{cm}^{-2} \mathrm{~s}^{-1}\end{array}$ & Elements \\
\hline 1 & Dy, Eu \\
\hline $1-10$ & In, Lu, Mn \\
\hline $10-10^{2}$ & $\mathrm{Au}, \mathrm{Ho}, \mathrm{Ir}, \mathrm{Re}, \mathrm{Sm}, \mathrm{W}$ \\
\hline $10^{2}-10^{3}$ & $\mathrm{Ag}, \mathrm{Ar}, \mathrm{As}, \mathrm{Br}, \mathrm{Cl}, \mathrm{Co}, \mathrm{Cs}, \mathrm{Cu}, \mathrm{Er}, \mathrm{Ga}, \underset{\mathrm{Yb}}{\mathrm{Hf}} \mathrm{I}, \mathrm{La}, \mathrm{Sb}, \mathrm{Sc}, \mathrm{Se}, \mathrm{Ta}, \mathrm{Tb}, \mathrm{Th}, \mathrm{Tm}, \mathrm{U}, \mathrm{V}$ \\
\hline $10^{3}-10^{4}$ & Al, Ba, $\mathrm{Cd}, \mathrm{Ce}, \mathrm{Cr}, \mathrm{Hg}, \mathrm{Kr}, \mathrm{Gd}, \mathrm{Ge}, \mathrm{Zr}$, $\mathrm{Na}, \mathrm{Nd}, \mathrm{Ni}, \mathrm{Os}, \mathrm{Pd}, \mathrm{Rb}, \mathrm{Rh}, \mathrm{Ru}, \mathrm{Sr}, \mathrm{Te}, \mathrm{Zn}$, \\
\hline $10^{4}-10^{5}$ & Bi, Ca, K, Mg, P, Pt, Si, Sn, Ti, TI, Xe, Y \\
\hline $10^{5}-10^{6}$ & $\mathrm{~F}, \mathrm{Fe}, \mathrm{Nb}, \mathrm{Ne}$ \\
\hline $10^{7}$ & $\mathrm{~Pb}, \mathrm{~S}$ \\
\hline
\end{tabular}

Permission to use this table provided by M.D. Glascock, University of Missouri. Table can be found at http://archaeometry.missouri.edu/naa_overview.html. 


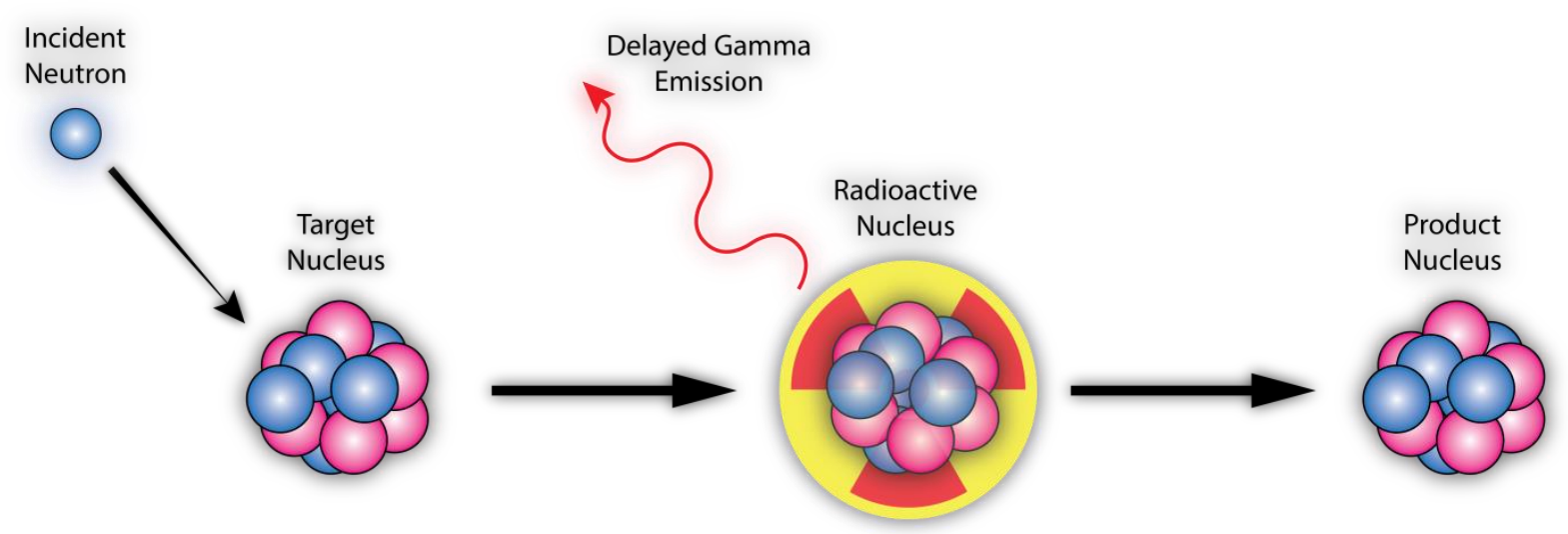

Figure 2-Theory of NAA. A target nucleus absorbs a neutron. This new isotope, which is radioactive with a suitably long half-life, eventually decays and emits a gamma ray in the process; the energy of this gamma ray is used to identify the original nucleus.

considered to be destructive. While the sample is still physically intact and whole after the irradiation, irreversible structural and chemical changes will have been introduced to the sample that may complicate follow-on analyses.

The safeguards utility of this technique is a broad, quantitative analysis of samples with virtually no sample preparation. Multiple samples can be irradiated in batches, reducing the total analysis time per sample. The technique also works as a bulk detection method where the entire sample is analyzed at once, eliminating the need for multiple measurements of a single sample. The detection limits of the technique are expected to be extremely low and accurate.

\subsection{HANDHELD RAMAN SPECTROSCOPY}

Raman spectroscopy uses the interaction of a laser with the electronic field and bonds of a molecule to determine information about the molecule's structure and identity. These measurements are performed by examining the wavelength shift of inelastically scattered laser light as it interacts with a target material, which is dependent on vibrational transitions within the molecule. If the laser light interacts with a Raman active molecule in the basic vibrational state, rather than re-emitting the laser light at the same frequency (Rayleigh scattering), the photon will lose some energy to the Raman vibrational mode and be emitted with a slightly lower energy, known as a Stokes shift. If the molecule was already in the excited mode, the emitted photon will have a slightly greater energy than the incident beam, known as anti-Stokes shifting.

The resulting spectrum (both above and below the Rayleigh line) can then be analyzed against known standards and theoretical calculations to identify and quantify chemical species. These transitions are shown in Figure 3. The use of a benchtop or handheld Raman probe may be able to identify safeguards-relevant compounds at concentrations found in environmental swipe samples (Figure 4). Handheld instruments may be able to provide in-field or on-receipt 


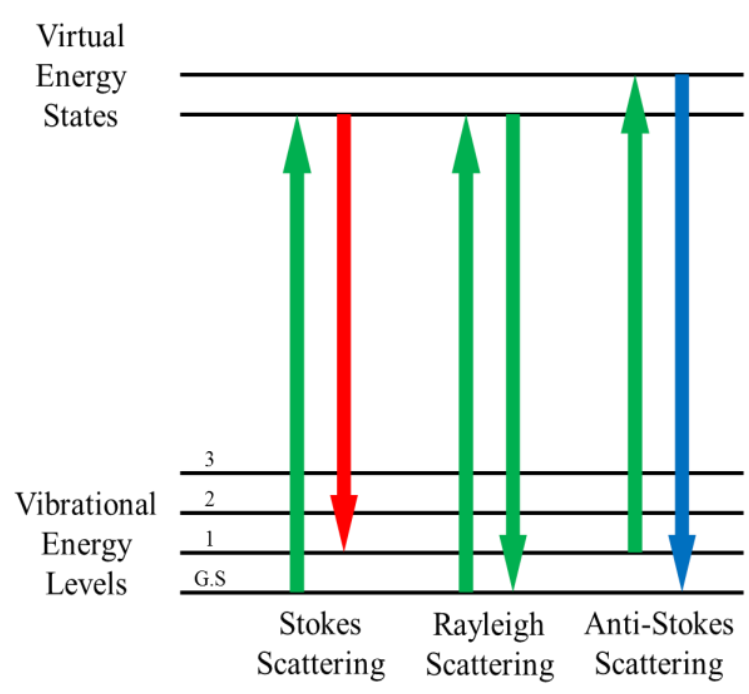

Figure 3-Theory of Raman spectroscopy. As a molecule absorbs a photon, depending on the vibrational energy state of the molecule, the reemitted photon will have one of three energies corresponding to Stokes, Rayleigh, and antiStokes scattering.

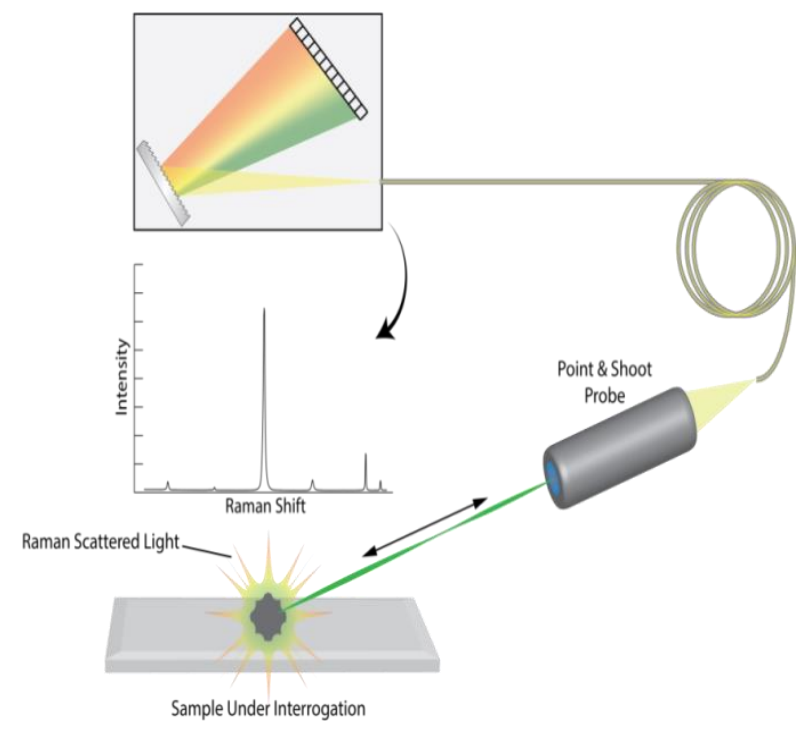

Figure 4-Point-and-shoot Raman principles. The examination of target materials uses a handheld probe to supply the excitation source and collect Raman-scattered light for analysis.

measurements quickly prior to other measurements. As shown in Table 2, several compounds of safeguards interest have Raman active lines that can be readily measured.

\subsection{CONFOCAL RAMAN MICROSCOPY}

Using the same principles of Raman spectroscopy (Section 2.5), confocal Raman uses optical microscope components to focus the excitation laser and collection optics on a small area, as shown in Figure 5. This simultaneously increases the laser fluence on the sample and reduces the background signal, resulting in a net increase in the technique's sensitivity. The tradeoff for this increased sensitivity is that a thorough scan will take a significant amount of time, on the order of hours per sample. Despite this, confocal Raman systems have been gaining in popularity to create surface maps of chemical species on a given substrate using automated sample stages and control software. This allows the user to map a surface with respect to a wavenumber corresponding to a particular chemical species. A complete confocal Raman spectrometer generally consists of a laser module, microscope hardware, laser enclosure, and imaging system.

Confocal Raman spectroscopy has the ability to identify very small amounts of material present on a sample due to the extremely limited field of view of the instrument. In this sense, the system would be able to detect materials on samples where the average analyte concentration is low, but the local concentration is high. This distribution is commonly found on samples that contain particulate materials, rather than previously liquid or gaseous samples. Therefore, samples that may not appear to have measurable signals from other pre-screening techniques 
Table 2-Raman active bands of safeguards-relevant species.

\begin{tabular}{ccccccc}
\hline Species & $\begin{array}{c}\text { Raman Band } \\
\left(\mathbf{c m}^{-1}\right)\end{array}$ & Reference & & Species & $\begin{array}{c}\text { Raman Band } \\
\left(\mathbf{c m}^{-1}\right)\end{array}$ & Reference \\
\hline $\mathrm{UF}_{4}$ & 915 & Pointurier 2010 & & $\mathrm{ThO}_{2}$ & 465 & Begun 1990 \\
$\mathrm{UO}_{2}$ & 445 & Pointurier 2010 & & TBP & 1,454 & Gantner 1985 \\
$\mathrm{UO}_{3}$ & 845 & Pointurier 2010 & & TBP & 1,304 & Gantner 1985 \\
$\mathrm{PuO}_{2}$ & 476 & Sarsfield 2012 & & TBP & 1,123 & Gantner 1985 \\
$\mathrm{NpO}_{2}$ & $463-468$ & Sarsfield 2012 & & TBP & 835 & Gantner 1985 \\
\hline
\end{tabular}

(such as gross alpha/beta spectroscopy) may show signals in well-defined locations with higher local concentrations.

The safeguards impact of this technology would be to localize Ramanactive species (see Table 2) on an environmental sample for further analysis. Due to the time investment of a complete chemical map, this technique would almost certainly need to be paired with another technology so that interesting samples would be mapped. It would function in a similar method to fission track analysis for hot particle detection without the need to irradiate the sample.

\subsection{FLUORESCENCE MICROSCOPY}

Fluorescence spectroscopy is a method that probes the emission of light from certain materials that occur as those materials undergo electronic transitions. To describe this approach, consider a simplified Jablonski diagram of the possible transition processes that can occur in a material (Figure 6). In this

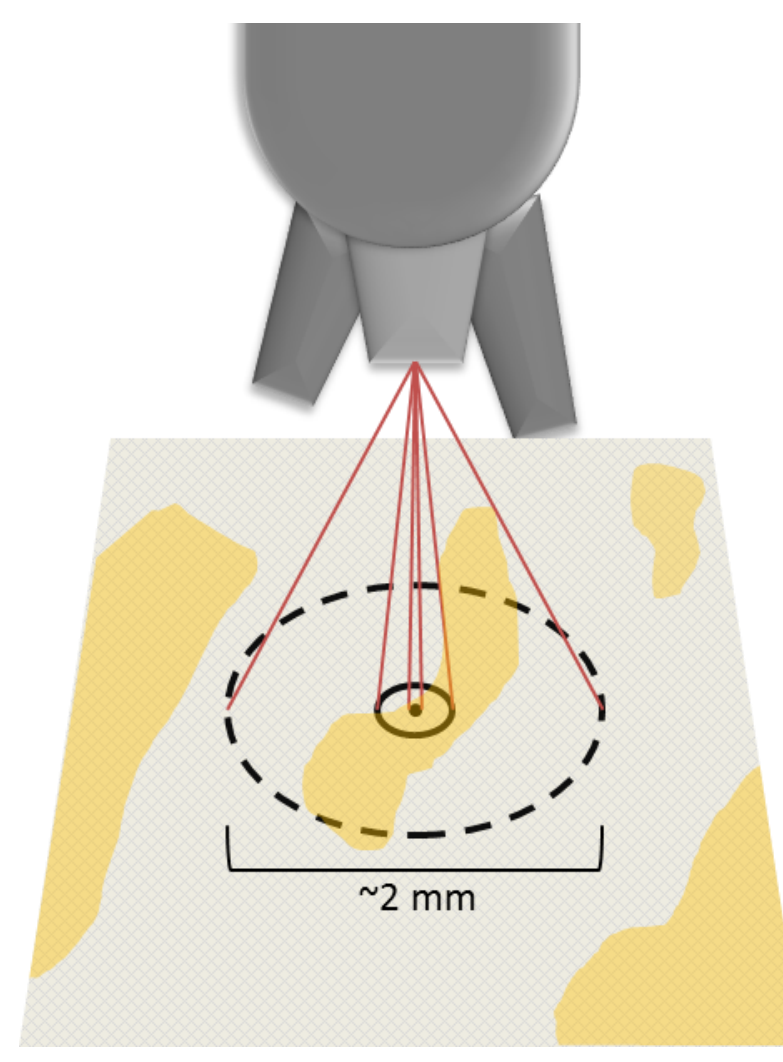

Figure 5-Principles of Confocal Raman

Microscopy. The three circles correspond to the field of view for three different objective lenses, each of which might detect a different concentration of analyte. technique, a target material is illuminated with a wavelength of light matching (or blue-shifted from) an electronic absorption band within the substance. Upon the absorption of a photon, an electron in the material is elevated from the $S_{0}$ to the $S_{1}$ excited electronic state. At this point, the molecule may undergo a number of processes, but the relevant event is the emission of a photon as the electron transitions from the $S_{1}$ to the $S_{0}$ state, known as fluorescence. This photon will be of a longer wavelength than the excitation source (red-shifted) and can be filtered and subsequently detected for quantitative or imaging purposes. The fluorescence spectra obtained can be used to identify and quantify chemical species of safeguards interest. 


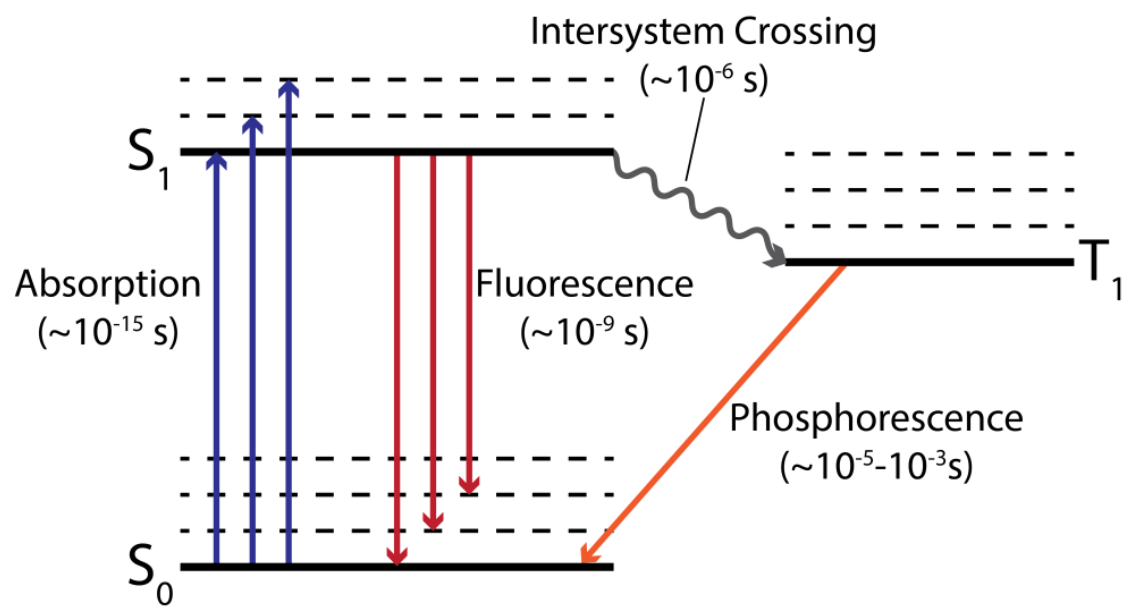

Figure 6-Jablonski diagram. This diagram illustrates the absorption and emission processes in a fluorescent/phosphorescent material.

Fluorescence microscopy integrates this technique into microscope optics, similar to confocal Raman spectroscopy. As in that case, this integration increases the laser fluence on the sample while reducing the possible background contribution. The configuration also shares the drawback that multiple samples will need to be collected to measure the entire surface of the swipe sample. Detection limits for fluorescence microscopy can reach the single-molecule level; however, there are known interferences that will be present for swipe analysis. Both the bag material and the cotton swipe fluoresce, requiring filtering techniques to be applied.

The safeguards utility of this technique is to scan for, identify, and quantify fluorescent molecules that have safeguards significance. Like Raman spectroscopy, this technique relies on the target's chemical identity; notably, the uranyl ion is fluorescent and can be readily detected by fluorescence spectroscopy.

\subsection{ATR INFRARED SPECTROSCOPY}

Infrared spectroscopy operates by probing molecular vibrational transitions with IR light. The molecule will absorb wavelengths that correspond to molecular vibrational modes (bends, stretches, etc.), rather than electron excitation, as in ultraviolet-visible spectroscopy. These specific vibrational modes can be used to compile a characteristic spectrum of a molecule. For these measurements, a spectrophotometer measures the differential transmission of IR radiation through the sample in comparison to a reference as a function of wavelength.

Similar to Raman and fluorescence spectroscopy, IR can provide chemical information of safeguards relevance. The near-IR region $(800 \mathrm{~nm}$ to $2,500 \mathrm{~nm})$ contains vibrations corresponding to several U compounds. While the plastic bags used to contain the environmental swipes no not interfere with the IR absorption of U compounds, the physical presence of the plastic bag may pose some sampling issues. The limits of detection for this technique with regard 
to swipe samples are uncertain, as IR is generally used as a bulk assay of relatively concentrated materials.

Attenuated total reflectance (ATR) is a method of introducing samples to an IR spectrometer. In this method, the sample is placed in contact with the window and the IR beam is passed through a crystal (e.g., diamond, zinc selenide), which reflects the beam internally. Every alternate reflection is in contact with the sample, which then absorbs some of the IR light; this absorbance is reflected in the final spectrum. For solid samples, an anvil may be used to push the sample against the crystal face. 


\section{EXPERIMENTAL RESULTS}

In FY15, multiple techniques were tested; some techniques showed more promise than others. In this section, all experimental work is detailed, with preference given to those techniques that showed the most promise for detecting trace levels of materials on environmental swipe samples.

\subsection{SIMULATED IAEA SWIPE SAMPLES}

The blank swipes were provided by Pacific Northwest National Laboratory (PNNL) and came from Texwipe Lot TX 304 L308, which has previously been analyzed by PNNL and determined to have about $2.5 \mathrm{ng}$ of natural U. The PNNL Sequim Marine Research Operations laboratory provided plastic bags, which are the same as those used to package swipe kits for IAEA inspections. This ensured that the simulated samples were identical to "real" swipe samples. Each new swipe was double bagged in the Oak Ridge Class 100 clean room. Each swipe was initially placed in a new 6-in. by 6-in. inner bag, which was then placed in an 8-in. by 8 -in. outer bag. Both the inner and outer bags are 4 mil thick. Initially, sets of approximately 12 swipes were distributed to the research groups for initial testing of blanks (i.e., geometry optimization and background minimization). Additional bagged swipes were then produced in the clean room and distributed for the mock sample loading.

Three sets of nine cotton swipes were made for this project. Each swipe had a single component added to it to minimize cross-contamination and reduce the potential false-positive rate. The swipe composition is detailed in Table 3; the concentration values assume that the materials were evenly spread over a $20-\mathrm{cm}^{2}$ circular area (about 2-in. diameter). Each swipe was made by placing $1 \mathrm{~mL}$ of a stock solution on a swipe and allowing it to dry in a clean environment. Duplicate swipes were made for each site to allow concurrent analyses. In addition, a blank swipe was provided, as well as a swipe with $1 \mathrm{~mL}$ of deionized water. A separate set of swipes was sent to each research group for testing. Selected swipes from each group were sent to the Oak Ridge NWAL for analysis. A noticeable coffee-ring effect was noted by researchers at both laboratories. This could have had the effect of making the samples non-homogeneous on the

Table 3-Composition of inter-comparison swipes.

\begin{tabular}{cccc}
\hline Chemical & $\begin{array}{c}\text { Chemical } \\
\text { Unit }\end{array}$ & $\begin{array}{c}\text { Total Material } \\
\mathbf{( g )}\end{array}$ & $\begin{array}{c}\text { Estimated Spot } \\
\text { Concentration }\left(\mathbf{g} / \mathbf{c m}^{2}\right)\end{array}$ \\
\hline $99.9 \%$ Deuterated water & $\mathrm{D}_{2} \mathrm{O}$ & 1.1 & $5.5 \times 10^{-2}$ \\
\hline Uranyl nitrate & $\mathrm{U}$ & $6.1 \times 10^{-2}$ & $3.1 \times 10^{-3}$ \\
Uranyl fluoride & $\mathrm{U}$ & $3.3 \times 10^{-6}$ & $1.7 \times 10^{-7}$ \\
Lithium hydroxide & $\mathrm{Li}$ & $2.0 \times 10^{-3}$ & $1.0 \times 10^{-4}$ \\
Calcium nitrate & $\mathrm{Ca}$ & $1.0 \times 10^{-6}$ & $5.0 \times 10^{-8}$ \\
Magnesium nitrate & $\mathrm{Mg}$ & $1.0 \times 10^{-6}$ & $5.0 \times 10^{-8}$ \\
\hline Tri-n-butyl phosphate & $\mathrm{TBP}$ & $9.8 \times 10^{-1}$ & $4.9 \times 10^{-2}$ \\
\hline
\end{tabular}


swipes and concentrating the sample material in the ring. As this is an artifact of the way the swipes were prepared, this effect would not be expected in real samples. However, the nonhomogeneity of the materials would be expected. Future studies may need to investigate a new method to create standards on cotton swipes.

\subsection{NWAL ANALYSIS}

The list of samples submitted to the NWAL for analysis is listed in Table 4. For the mock samples, the values in the "expected U content" column comes from the expected amount and type of material that was loaded on blank swipes. The "travel" blanks are unopened blank swipes that traveled with each of the three sample sets to Argonne, Oak Ridge, and the University of Wisconsin-Madison (UW). Their purpose is to identify any contamination that may have been introduced from the cross-country travel and the use of the pre-screening techniques. A clean travel blank would indicate that the additional handling of these swipe sets did not compromise them with respect to their $U$ content or isotopic composition. Additional blank swipes were introduced by the CIMS lab just prior to analysis of the samples to monitor cleanliness during sample dissolution and actinide separation.

Table 4-List of swipes submitted for NWAL analysis.

\begin{tabular}{|c|c|c|}
\hline Swipe ID & Expected U Content & $\begin{array}{l}\text { Laboratory } \\
\text { Processed }\end{array}$ \\
\hline ANL "travel" blank & Blank ( 2.5 ng U) & Clean Room \\
\hline ANL deionized $\mathrm{H}_{2} \mathrm{O}$ & Blank ( 2.5 ng U) & Clean Room \\
\hline ANL $\mathrm{UO}_{2} \mathrm{~F}_{2}$ & $10 \mu \mathrm{g}$ natural $\mathrm{U}$ & Clean Room \\
\hline $\mathrm{ANL} \mathrm{UO}_{x}\left(\mathrm{NO}_{3}\right)_{y}$ & $67 \mathrm{mg} \mathrm{DU}$ & Low-Level Rad Lab \\
\hline ORNL "travel" blank & Blank ( 2.5 ng U) & Clean Room \\
\hline ORNL LiOH & Blank ( 2.5 ng U) & Clean Room \\
\hline ORNL $\mathrm{UO}_{2} \mathrm{~F}_{2}$ & $10 \mu \mathrm{g}$ natural $\mathrm{U}$ & Clean Room \\
\hline UW "travel" blank & Blank ( 2.5 ng U) & Low-Level Rad Lab \\
\hline UW irradiated blank $A$ & Blank ( 2.5 ng U) & Low-Level Rad Lab \\
\hline UW irradiated blank B & Blank ( 2.5 ng U) & Low-Level Rad Lab \\
\hline UW $1 \mu \mathrm{g} \mathrm{Ca}$ & Blank ( 2.5 ng U) & Low-Level Rad Lab \\
\hline UW UO $\left(\mathrm{NO}_{3}\right)_{y}$ & $10 \mathrm{ng}$ DU & Low-Level Rad Lab \\
\hline $\mathrm{UW} \cup \mathrm{OO}_{x}\left(\mathrm{NO}_{3}\right)_{y}$ & 100 ng DU & Low-Level Rad Lab \\
\hline
\end{tabular}


For the ashing and chemical processing, the swipes were segregated based on the expected content. Most samples were ashed and processed in Oak Ridge building 1005, the Ultra-Trace Forensic Science Center, which contains both Class 100 and Class 1000 clean rooms. The sample with $67 \mathrm{mg}$ of $U$ had too high a $U$ content to bring into building 1005, so it was processed in a low-level radiological laboratory. Additionally, the swipes that were irradiated at UW showed low but measurable amounts of activity, also necessitating their processing in the same low-level radiological laboratory.

In general, the swipes ashed as expected. The one exception was the 67-mg sample, which appeared to "caramelize" during the ashing process. The sample is pictured on the left in Figure 7 alongside a blank swipe that was ashed simultaneously. Because of this observation, the sample was re-ashed overnight two additional times to try to complete the destruction of the cotton matrix. Eventually the dissolution process was continued, and the sample readily dissolved in nitric acid. Figure 8 shows the sample and the blank dissolved in Teflon vials. The yellow color of the sample is due to the high $U$ content, but the absence of any solids in the bottom indicates that a complete dissolution was achieved. Thus all the prepared samples were shown to be compatible with the Oak Ridge NWAL ashing process.

The results of the NWAL analysis for the selected swipes are displayed in Table 5. The table includes the 13 submitted samples, along with blank swipes (CIMS blanks) added by the CIMS group as additional chemistry controls. The ${ }^{234} U /^{238} \mathrm{U},{ }^{235} \mathrm{U} /{ }^{238} \mathrm{U}$, and ${ }^{236} \mathrm{U} /{ }^{238} \mathrm{U}$ ratios and the $\mathrm{U}$ content (in $\mathrm{ng}, \mu \mathrm{g}$, or $\mathrm{mg}$ ) are stated for each sample and blank. For reference, the PNNL isotopic and $\mathrm{U}$ content of the swipe materials are displayed on the first line of the table.

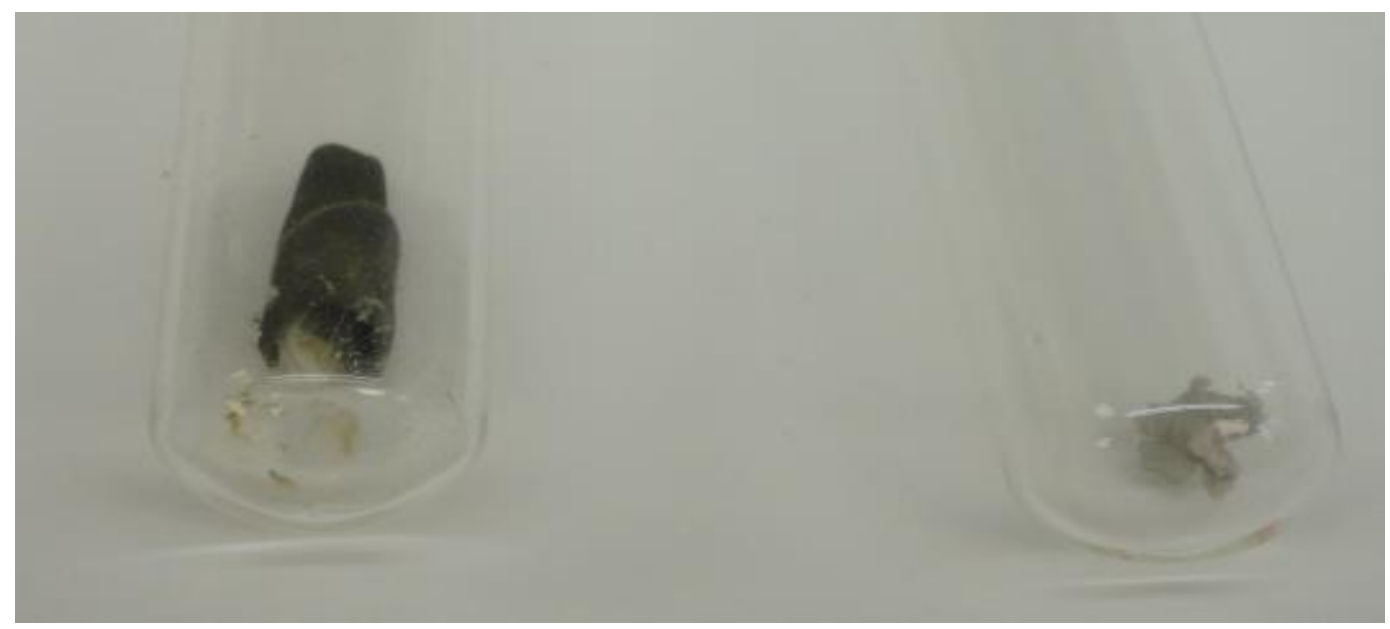

Figure 7-Ashed Argonne samples. The sample on the left contains the 67-mg DU swipe, and the sample on the right is a blank swipe. 


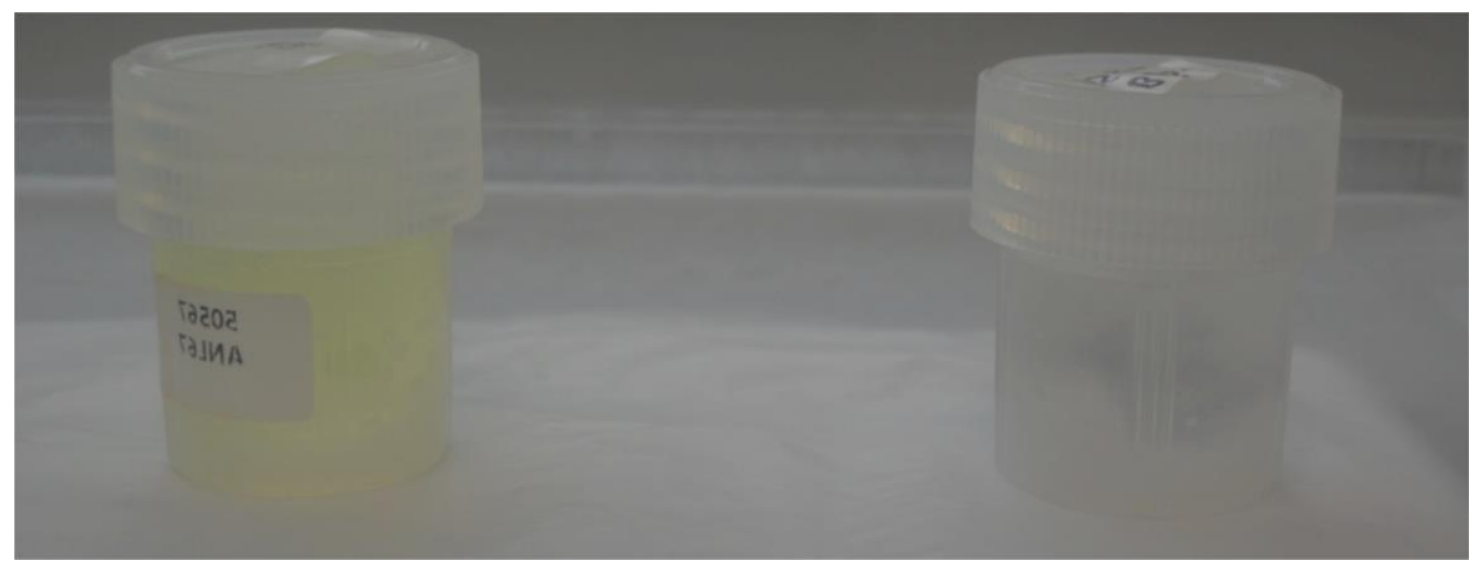

Figure 8-Dissolved Argonne samples. The sample on the left contains the 67-mg DU swipe and the sample on the right is a blank swipe.

\subsubsection{Uranium Content}

The U content for most samples is exactly what was anticipated. The blanks, as well as samples loaded with material other than U, contained approximately $2.5 \mathrm{ng}$ of $\mathrm{U}$. The highest swipe measured here contained $2.7 \mathrm{ng}$, and the lowest $2.2 \mathrm{ng}$. The U content within a given lot of Texwipes is known to vary slightly, so these results overall show excellent agreement with the expected values.

Likewise, the UW samples that were loaded with 10 and $100 \mathrm{ng}$ of U showed good agreement with the expected values. Because the swipes themselves contain $\sim 2.5 \mathrm{ng}$ of $\mathrm{U}$, the measurement of $15.2 \mathrm{ng} \mathrm{U}$ on the "UW $10 \mathrm{ng}$ " sample suggests that about $12.7 \mathrm{ng}$ of material was actually loaded. This difference is likely within the expected uncertainty of the loading for this small amount of sample. The UW sample loaded with $100 \mathrm{ng}$ was measured at $99.5 \mathrm{ng}$, matching the expected value nicely.

The samples loaded with higher levels of material show slightly more deviation from the expected values. Both the Argonne and Oak Ridge samples nominally loaded with $10 \mu \mathrm{g}$ of $\mathrm{U}$ actually contained only about $3.3 \mu \mathrm{g}$ of $\mathrm{U}$. Both of the samples analyzed, from the two different sample sets, contained very similar amounts of $U$. The high precision of the replicate measurements likely indicates that the true loading was closer to $3 \mu \mathrm{g}$ rather than $10 \mu \mathrm{g}$, but it is also possible that some portion of the $U$ added to the swipe was in a form that was incompatible with the NWAL chemistry, meaning that only a portion of the actual sample was measured. A more careful characterization of this source material is recommended if it is to be used in the future.

The final swipe is the one loaded with an expected $67 \mathrm{mg}$ of U. It was measured to contain about $61 \mathrm{mg}$ of $\mathrm{U}$, close to the expected value. Analyses of this type, where a sample contains very high amounts of $U$, are known to result in measured values that tend to be about $10 \%$ low due to the difficulty of getting and keeping such a large amount of $U$ in solution in a relatively small volume. Thus, the discrepancy here is not entirely surprising and does not 
Table 5-NWAL analysis results.

\begin{tabular}{|c|c|c|c|c|c|c|c|c|}
\hline Sample & $1:{ }^{234} U /{ }^{238} U$ & 2 Sigma & $2:{ }^{235} \mathrm{U} /{ }^{238} \mathrm{U}$ & 2 Sigma & $3:{ }^{236} U /{ }^{238} \mathrm{U}$ & 2 Sigma & [U], $\mathbf{n g}$ & 2 Sigma \\
\hline PNNL swipes & 0.0000769 & 0.0000026 & 0.007199 & 0.000026 & 0.00000112 & 0.00056 & 2.5481 & 0.0032 \\
\hline CIMS blank & 0.0000807 & 0.0000016 & 0.007329 & 0.000028 & 0.00000108 & 0.00000022 & 2.542 & 0.057 \\
\hline ANL travel blank & 0.0000743 & 0.0000012 & 0.007244 & 0.000025 & 0.00000147 & 0.00000012 & 2.745 & 0.062 \\
\hline ANL $\mathrm{H}_{2} \mathrm{O}$ & 0.0000790 & 0.0000017 & 0.007318 & 0.000022 & 0.00000128 & 0.00000017 & 2.205 & 0.050 \\
\hline ORNL travel blank & 0.0000785 & 0.0000023 & 0.007299 & 0.000023 & 0.00000066 & 0.00000016 & 2.270 & 0.051 \\
\hline CIMS blank & 0.0000814 & 0.0000027 & 0.007464 & 0.000034 & 0.00000138 & 0.00000031 & 2.631 & 0.059 \\
\hline ORNL LiOH & 0.0000779 & 0.0000018 & 0.007382 & 0.000026 & 0.00000687 & 0.00000052 & 2.611 & 0.059 \\
\hline UW trip blank & 0.0000845 & 0.0000032 & 0.007839 & 0.000038 & 0.00000293 & 0.00000076 & 2.374 & 0.054 \\
\hline UW trip blank A Irr. & 0.0000864 & 0.0000032 & 0.008035 & 0.000044 & 0.00000349 & 0.00000068 & 2.336 & 0.053 \\
\hline UW trip blank B Irr. & 0.0000769 & 0.0000029 & 0.007177 & 0.000035 & 0.00000068 & 0.00000019 & 2.330 & 0.053 \\
\hline 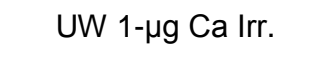 & 0.0000861 & 0.0000011 & 0.008205 & 0.000021 & 0.00000365 & 0.00000028 & 2.498 & 0.057 \\
\hline UW 100-ng U Irr. & 0.0000168 & 0.0000015 & 0.003231 & 0.000015 & 0.00004367 & 0.00000208 & 99.5 & 2.2 \\
\hline \multirow[t]{2}{*}{ UW 10-ng U Irr. } & 0.0000275 & 0.0000015 & 0.004893 & 0.000029 & 0.00005077 & 0.00000320 & 15.20 & 0.34 \\
\hline & & & & & & & {$[\mathrm{U}], \mu \mathrm{g}$} & \\
\hline ANL $10-\mu \mathrm{g} \cup \mathrm{O}_{2} \mathrm{~F}_{2}$ & 0.0000617 & 0.0000022 & 0.008175 & 0.000032 & 0.00000083 & 0.00000016 & 3.358 & 0.076 \\
\hline \multirow[t]{2}{*}{ ORNL $10-\mu \mathrm{g} \cup \mathrm{O}_{2} \mathrm{~F}_{2}$} & 0.0000622 & 0.0000023 & 0.008135 & 0.000025 & 0.00000102 & 0.00000024 & 3.371 & 0.076 \\
\hline & & & & & & & [U], mg & \\
\hline CIMS blank & 0.0000141 & 0.0000007 & 0.002838 & 0.000015 & 0.00004166 & 0.00000186 & 0.0002450 & 0.0000055 \\
\hline ANL 67-mg UO ${ }_{x}\left(\mathrm{NO}_{3}\right)_{y}$ & 0.0000131 & 0.0000008 & 0.002779 & 0.000020 & 0.00004237 & 0.00000130 & 61.3 & 1.4 \\
\hline
\end{tabular}


indicate any significant source of concern. Also of note here, the blank swipe that was processed with this sample shows about $250 \mathrm{ng}$ of $\mathrm{U}, 100$ times higher than expected on a blank swipe. However, as can be seen from the isotopic values discussed in Section 3.2.2, the blank simply picked up U from the high-level sample it was processed with. Again, this is commonly seen in samples with extremely high concentrations. The fact that the blank picked up only about $0.0004 \%$ of the $U$ in the sample is a testament to the cleanliness of the chemistry, and it is well within acceptable tolerances.

\subsubsection{Isotopic Analysis}

The isotopic results, also presented in Table 5, show a picture similar to that of the U content. The blanks and the swipes loaded with material other than $U$ have isotopic values that match the PNNL analysis for this lot of Texwipes. The ${ }^{235} \mathrm{U} /{ }^{238} \mathrm{U}$ ratios are all very close to the value for natural $\mathrm{U}$, as expected. The ${ }^{234} \mathrm{U} /{ }^{238} \mathrm{U}$ ratios are slightly elevated versus natural $\mathrm{U}$, but this is a typical result for cotton swipes from this manufacturer and is also reflected in the PNNL analysis. The ${ }^{236} \mathrm{U} /{ }^{238} \mathrm{U}$ ratio across the blanks also matches the PNNL value and essentially represents a non-detection of the ${ }^{236} \mathrm{U}$ isotope. The very small ratio measured for ${ }^{236} \mathrm{U} /{ }^{238} \mathrm{U}$ is attributed to the low energy tail of the ${ }^{238} \mathrm{U}$ ion beam producing counts in the ${ }^{236} \mathrm{U}$ mass channel in the mass spectrometer and not to the presence of detectable ${ }^{236} \mathrm{U}$.

There are two exceptions to this, the first being the swipes that were sent to the reactor at UW. In this case, most of the blanks show slightly elevated $U$ isotopic ratios for both ${ }^{234} U /{ }^{238} U$ and ${ }^{235} \mathrm{U} /{ }^{238} \mathrm{U}$. The ${ }^{236} \mathrm{U} /{ }^{238} \mathrm{U}$ ratio also appears elevated versus the other blanks in these samples, although again most of this is attributed to peak tailing in the instrument and not to actual ${ }^{236} \mathrm{U}$. The slight enrichment of the samples is even seen for the travel blank, which was not irradiated. Interestingly, UW trip blank B, which was irradiated, shows isotopic values essentially the same as the PNNL characterization. These findings likely point to a slight amount of contamination in some of these samples. At a total $U$ content of $2.5 \mathrm{ng}$, it only takes $2 \mathrm{pg}$ of ${ }^{235} \mathrm{U}$ to skew an isotopic measurement from the natural value of 0.0072 to 0.0080 , where most of these blanks were measured. Whether the contamination occurred from the initial loading of the swipes, additional handling of the swipes during transport, the actual irradiation and measurements at the reactor, from the chemical processing, or from the mass spectrometry is unclear at this point. The fact that the travel blank was contaminated while one of the irradiated ones was not makes the problem even more complex. However, as mentioned above, these samples were processed in a low-level radiological facility rather than the typical clean room because of the measurable activity from the irradiation, which could be the reason for this slight contamination.

The second exception is the blank that was processed alongside the 67-mg sample. As mentioned in Section 3.2.1, this swipe clearly picked up material from the sample, which is expected with the levels of $U$ that were present in this particular sample. The consistency of the isotope ratios between the sample and the blank indicate that the depleted material found on the blank swipe originated from the sample and does not represent any other source of contamination. 
The values for the samples loaded with $\mathrm{U}$ are generally consistent with expected values as well. Because none of the source material was characterized prior to loading, there is no "known" value with which to compare for any of these samples. However, the $\mathrm{UO}_{2} \mathrm{~F}_{2}$ was supposed to be "natural" U, while the $\mathrm{UO}_{\mathrm{x}}\left(\mathrm{NO}_{3}\right)_{\mathrm{y}}$ was "depleted" uranium (DU). The Argonne and Oak Ridge 10- $\mu \mathrm{g} \mathrm{U}$ samples $\left(\mathrm{UO}_{2} \mathrm{~F}_{2}\right)$ thus should have had a ${ }^{235} \mathrm{U} /{ }^{238} \mathrm{U}$ ratio of about 0.0072 . However, both samples were measured at about 0.0081, indicating a slight enrichment. The consistency of these replicate measurements suggests that the material actually loaded onto the swipes was enriched, rather than contamination occurring somewhere in the handling, which would show more variability. The relatively high $U$ content here (micrograms) would require a very significant contamination event to perturb the isotopic ratios, on the order of tens of nanograms of ${ }^{235} \mathrm{U}$. This is extremely unlikely, especially considering that the samples were processed in a Class 1000 clean room and that the chemistry blanks processed in the same facility showed no enrichment. The most likely scenario is that the starting material is slightly enriched. This could be verified by high-precision analysis (e.g., MC-ICPMS) of the starting material.

The final samples are those loaded with depleted $\mathrm{UO}_{\mathrm{x}}\left(\mathrm{NO}_{3}\right)_{\mathrm{y}}$ material. This includes the $10 \mathrm{ng}$ and $100 \mathrm{ng}$ loadings for the irradiated UW swipes and the 67-mg Argonne sample. As with the $\mathrm{UO}_{2} \mathrm{~F}_{2}$, this material was not specifically characterized before loading the swipes, so a direct comparison to "known" values is not possible. However, the material was expected to be depleted, and the analysis of all the samples shows this. The $67-\mathrm{mg}$ sample has a ${ }^{235} \mathrm{U} /{ }^{238} \mathrm{U}$ ratio of 0.00278, significantly lower than the natural value. The UW 100-ng and 10-ng samples have ${ }^{235} \mathrm{U} /{ }^{238} \mathrm{U}$ ratios of 0.00323 and 0.00489 , respectively. Both of these are depleted, as expected, and the apparent inconsistency between the values can be explained by considering the $2.5 \mathrm{ng}$ of natural $U$ mixed into the sample from the swipe itself. This natural $U$ perturbs the observed isotopic ratio of the smaller sample more than the larger sample, moving them both closer toward the natural value.

The consistency of the results for all the analyses, when compared to both expected values and to the intra-set replicate values, shows that all of these sample types and pre-screening methods are generally compatible with successful NWAL chemical processing and analysis. However, some recommendations are included for more definitive experiments if further evaluation of selected technologies occurs next year. First, careful characterization of the starting material is strongly recommended. This could include using isotopic standards or certified reference materials for the loading, or just a thorough MC-ICPMS analysis of the same materials used this year.

Second, the full chemical separation of both $\mathrm{U}$ and $\mathrm{Pu}$ is suggested. The reason for this is twofold. In the UW samples, it is possible that ${ }^{239} \mathrm{Pu}$ was created from the irradiation of ${ }^{238} \mathrm{U}$. The NWAL processing has very low Pu blank levels, so this investigation would reveal if the exposure in the reactor creates enough $\mathrm{Pu}$ to affect the Pu measurement. This has serious implications for the future use of NAA as a pre-screening tool. Second, carrying out the Pu chemistry has the added benefit of purifying thorium from the $U$ fraction. Some of the materials here had high ${ }^{232} \mathrm{Th}$, which precluded the analysis of ${ }^{233} \mathrm{U}$, which is typically measured. Removal of the ${ }^{232} \mathrm{Th}$ will allow the measurement of trace ${ }^{233} \mathrm{U}$ that may be produced by or present in the reactor. 
Finally, the level of $U$ loaded is much higher than what is typically found on real IAEA samples. Future samples could be loaded at lower levels to more accurately reflect the vast majority of swipes received at the NWAL. This would provide a more realistic test of the candidate technologies, as well as pose less risk to the clean rooms where samples will be processed.

\subsection{X-RAY FLUORESCENCE}

\subsubsection{Instrumentation}

This project primarily utilized an Olympus Innov-X Delta (DP4000-C) premium handheld XRF. While several alternatives are available, this handheld unit was well-suited for screening swipe samples in the field due to its point-and-shoot mode of operation, reasonable sensitivity and accuracy, durability, and portability. The DP4000-C has a gold anode to minimize interference with heavy elements, such as $\mathrm{U}$ and $\mathrm{Pu}$, and is customized with two pre-set analytical modes: soil mode and alloy mode. In alloy mode, one filter position is used, and it targets elements with ionization potentials of $15-30 \mathrm{keV}$ and then matches the measured spectrum to a database with hundreds of commonly manufactured alloys. In the soil mode, three different filters sets (referred to as "beams") are used that target different ionization potentials. Beam 1 is best suited to identifying elements with ionization potentials of $15-30 \mathrm{keV}$; beam 2, 6-15 keV; and beam 3, 2-7 keV.

In addition to the handheld device, Argonne had access to a Xenemetrix Genius IF EDXRF spectrometer. The Genius IF can operate in both direct excitation and secondary target excitation modes with eight secondary targets and filters. The unit incorporates a high-resolution silicon drift detector with a $0.125-\mathrm{keV}$ resolution, a $50-\mathrm{kV} / 50-\mathrm{W}$ variable-spot-size X-ray tube, and an eight-position autosampler. This unit was used to compare the sensitivity of the less expensive handheld unit to a research-grade benchtop unit.

\subsubsection{Analysis Methodology}

Samples were analyzed using the handheld unit operating in soil mode, chosen based upon the anticipated composition of the materials on the swipe and the particulate-like nature of the analytes. This analysis mode also collects all three beam profiles for a given spot, allowing for comparison and partial optimization. This mode also provides an automated analysis for elements within the device's library, which includes elements up to U.

Once spectra were collected, they were analyzed in Excel to identify peaks and elements. At this stage, no advanced smoothing and peak-finding algorithms (i.e., second derivative, deconvolution, etc.) were applied and peak identification was performed visually. Peak identity was made by comparing known X-ray emission patterns to the spectrum. This was aided by a custom analysis macro program. Once peaks were identified, if quantification was to be 
attempted, both peak height and peak areas were collected on standards and unknowns. For U samples, the manual analysis was compared to the automated analysis.

\subsubsection{Analysis of Particulates}

As part of a separate project (for DOE Office of Nuclear Energy), Argonne used the handheld XRF to measure frozen $\mathrm{SrCl}_{2} / \mathrm{KCl}$ droplets with an average diameter of $600 \mu \mathrm{m}$ for identification/quantification. These drops were cast on to a Kapton film from a microfluidic generator and placed on a flat slide for measurement. The particles were imaged using the onboard camera, allowing for a single particle to be analyzed at once. Table 6 shows the results of six separate droplets measured through a plastic bag. The video camera on the XRF instrument enabled us to isolate the XRF beam to measure just local area around the droplet. This illustrates the ability of the handheld XRF to identify small quantities of elements of interest present on double-bagged swipes.

\subsubsection{Initial Testing with Cobalt}

Initial tests were run with simulated cobalt swipes to confirm the handheld instrument could detect materials at areal concentrations consistent with expected swipe concentrations of material (tens to thousands of micrograms total) and to compare the performance of the handheld instrument with the benchtop instrument. Cobalt was chosen, as it has a strong IR absorption (see Section 3.8.2) and can be easily identified by XRF. Swipes were prepared by depositing cobalt nitrate nonahydrate on to Grade 41 ashless filter papers (Whatman) using a cotton swab. The filters were weighed before and after on a Mettler Toledo AT201 scale (resolution of $0.01 \mathrm{mg}$ ). A total of four swipes were prepared, three with $420 \mu \mathrm{g}, 110 \mu \mathrm{g}$, and $240 \mu \mathrm{g}$ of cobalt and a fourth swipe below measureable limits on the scale. These were then analyzed by the handheld and benchtop XRF devices. The results in Figures 9 and 10 clearly show that the handheld device is comparable in accuracy to the benchtop device at high concentrations but cannot achieve the same limits of detection. 


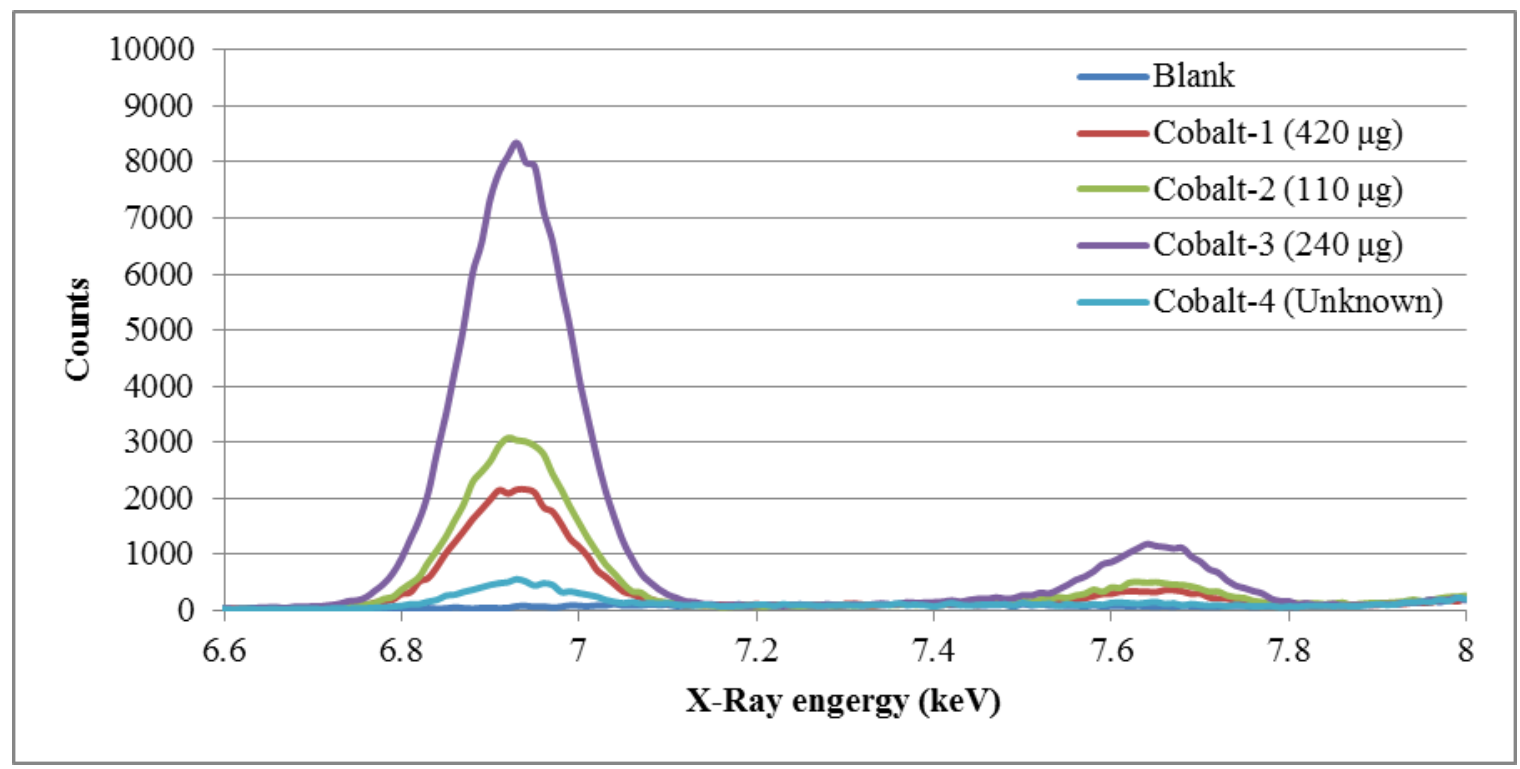

Figure 9-GeniusIF Cobalt results. Results from the GeniusIF XRF (operating in secondary electron mode) showing two peaks belonging to cobalt.

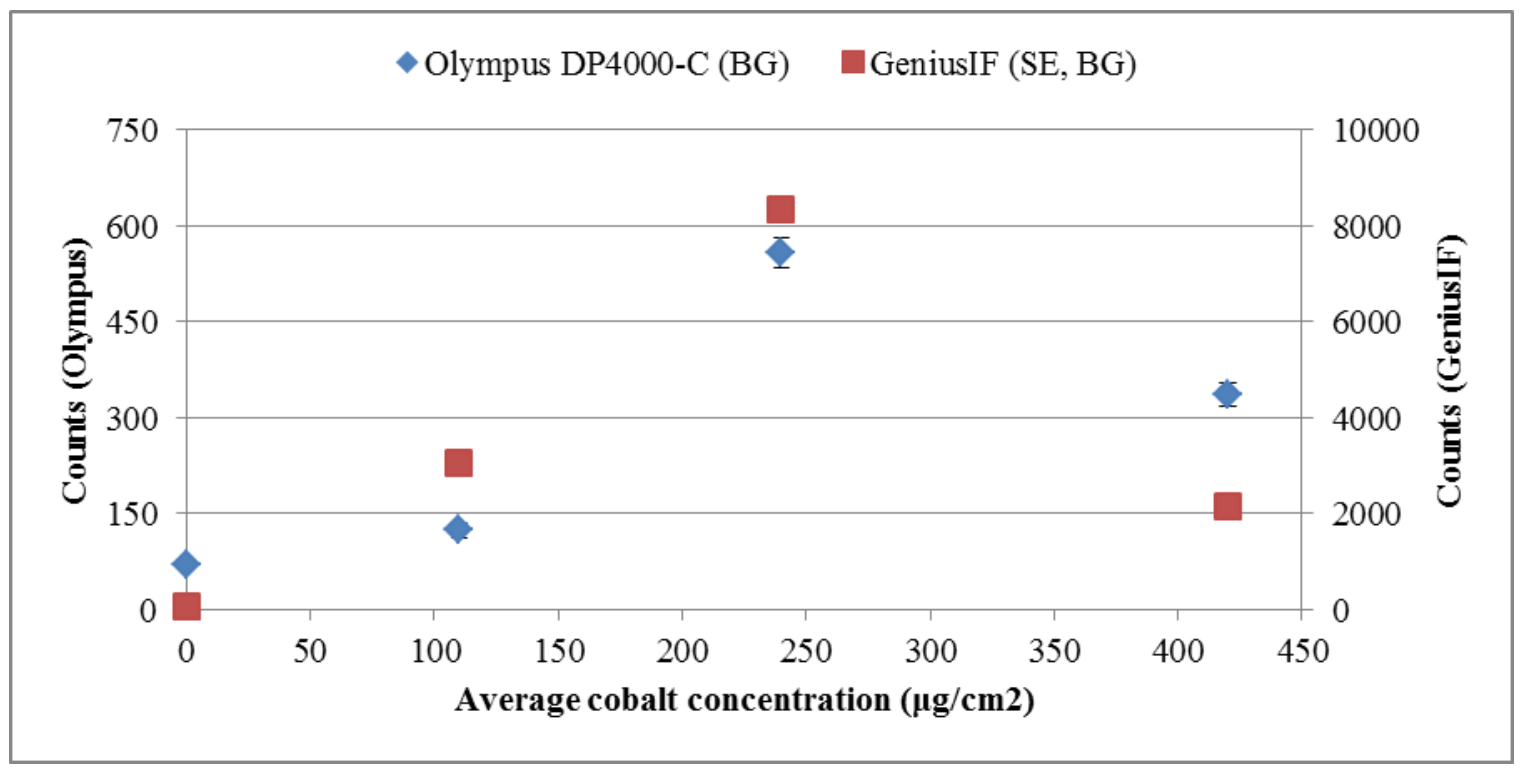

Figure 10-Comparison of handheld and benchtop XRFs. The results from Figure 9 are compared to the Olympus handheld. As expected, the benchtop model has a lower sensitivity due to a stronger X-ray source, which increases the signal received ( 15 -fold improvement). 


\subsubsection{Oak Ridge Standard Swipes}

The standard swipes prepared by Oak Ridge were also analyzed. Of these samples, only the uranyl nitrate $\left(3.3 \times 10^{-3} \mathrm{~g} / \mathrm{cm}^{2}\right)$ was immediately apparent (Figure 11). This sample produced very distinct $\mathrm{U}$ lines due to the very high concentration. The uranyl fluoride did not give the same results, mainly due to the 1,000 -fold decrease in concentration. The only other sample of interest was the Ca sample $\left(5.0 \times 10^{-8} \mathrm{~g} / \mathrm{cm}^{2}\right)$. It appears that all of the samples have a background contribution from $\mathrm{Ca}$ (possibly incorporated into the cotton matrix), with the exception of the $\mathrm{Mg}$ samples, which showed a reduced response. The Ca standards showed a small (15-20\%) increase in peak area as compared to the non-calcium, non-magnesium samples (Figure 12). While this increase is potentially significant, additional work may be able to increase the signal to noise and characterize the background $\mathrm{Ca}$ contribution. The $\mathrm{Ca}$ signal is therefore reserved as a potential signal.

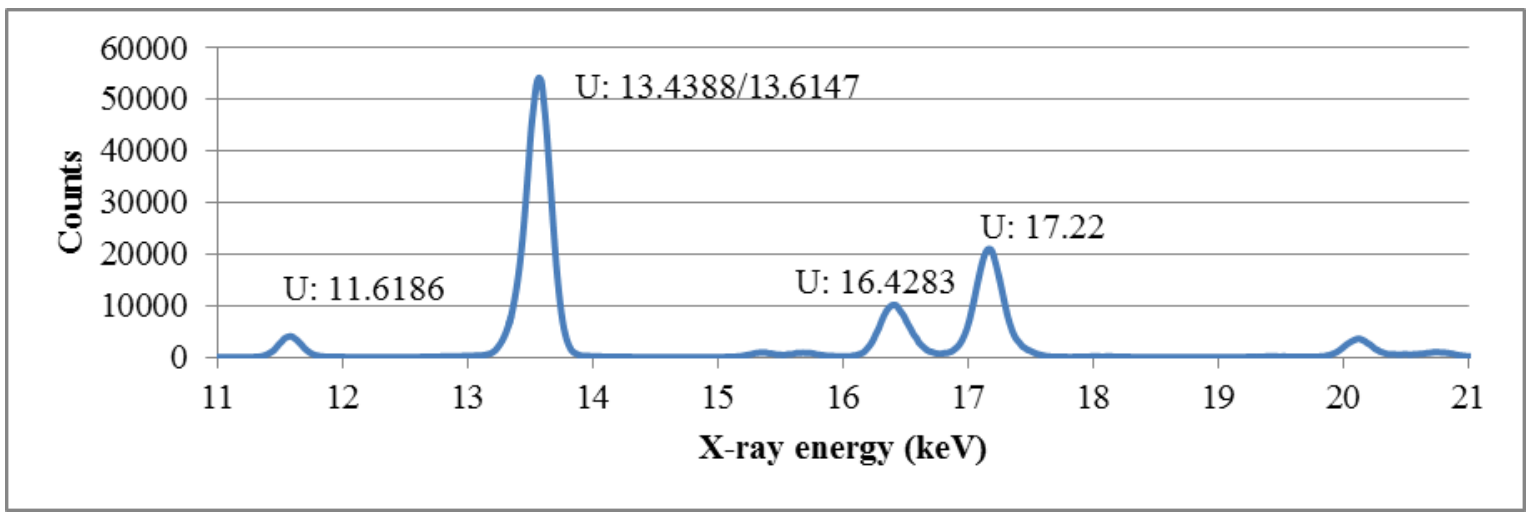

Figure 11-Uranium XRF spectrum.

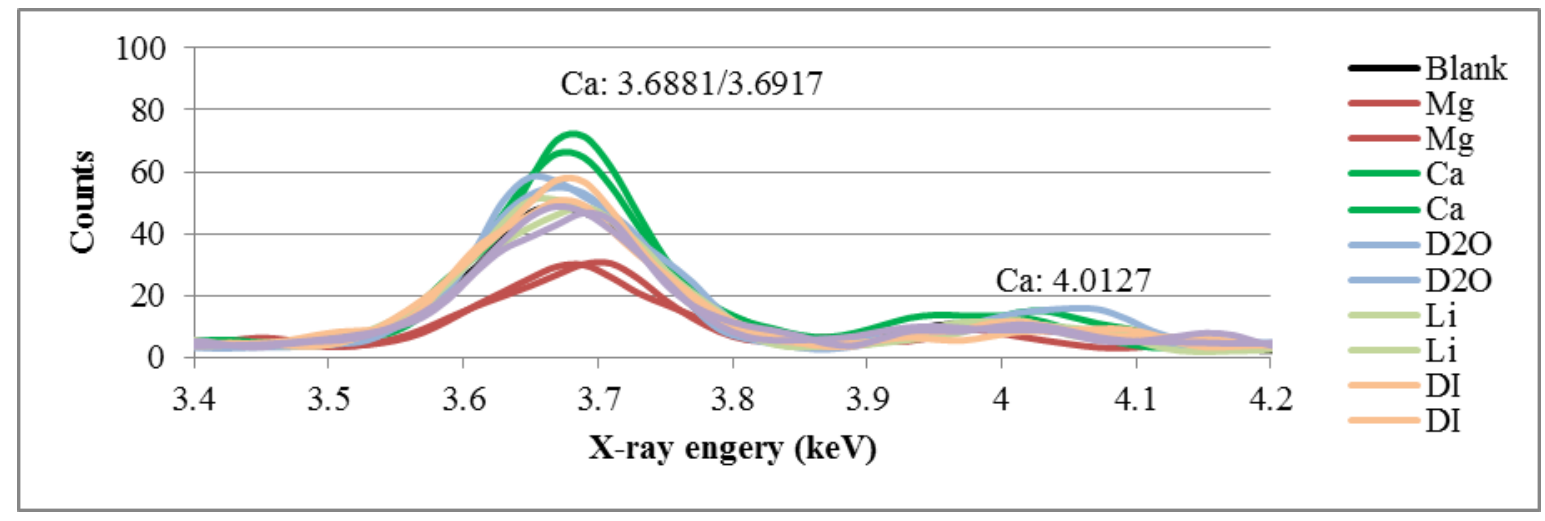

Figure 12-XRF spectra at the calcium line. 


\subsubsection{Uranium and Plutonium Standards}

Following the determination that the XRF could indeed detect larger concentrations of $U$ (via the Oak Ridge swipes), a set of lower-concentration swipes containing either U or Pu nitrate were created using a subdivided blank swipe provided by the Oak Ridge NWAL (Table 7). These swipes were created by dotting $100 \mu \mathrm{L}$ of solution onto the cotton and allowing it to dry; the dried samples were then double-bagged and analyzed. All samples were made from gravimetrically prepared standards. These standards resulted in $\sim 1-\mathrm{cm}$ diameter spots that could be analyzed as a whole. The results are also found in Table 7; for both sets, the fourth standard was essentially at background. The best fit in both cases $\left(\mathrm{R}^{2}>0.99\right)$ was obtained by using the peak area with no background subtraction. The regression results are provided without an error analysis in this case. A clear signal was obtained with the $16-\mu \mathrm{g} / \mathrm{cm}^{2} \mathrm{U}$ standard, and a possible signal was observed with the $28-\mu \mathrm{g} / \mathrm{cm}^{2} \mathrm{Pu}$ standard. Therefore, the limit of detection is estimated at about $20 \mu \mathrm{g} / \mathrm{cm}^{2}$ for $\mathrm{U}$ and about $40 \mu \mathrm{g} / \mathrm{cm}^{2}$ for Pu. Further work will be needed to refine these values; the estimates provided here are presented for estimation and planning purposes.

Table 7-Composition of U/Pu standards and handheld XRF results.

\begin{tabular}{|c|c|c|c|c|}
\hline & $\begin{array}{l}\mathrm{UO}_{2}\left(\mathrm{NO}_{3}\right)_{2} \\
\left(\mu \mathrm{g} / \mathrm{cm}^{2} \mathrm{U}\right)\end{array}$ & $\begin{array}{c}\mathrm{U}: \begin{array}{c}13.4388 / 13.6147 \\
\text { (counts) }\end{array} \\
\text { keV }\end{array}$ & $\begin{array}{c}\mathrm{Pu}\left(\mathrm{NO}_{3}\right)_{4} \\
\left(\mu \mathrm{c} / \mathrm{cm}^{2} \mathrm{Pu}\right)\end{array}$ & $\begin{array}{l}\text { Pu: } 14.234 \mathrm{keV} \\
\text { (counts) }\end{array}$ \\
\hline Standard 1 & 76 & 16,644 & 150 & 6,886 \\
\hline Standard 2 & 16 & 4,392 & 28 & 1,771 \\
\hline Standard 3 & 3.1 & 2,360 & 5.9 & 1,301 \\
\hline Standard 4 & 0.60 & 1,581 & 1.1 & 1,128 \\
\hline
\end{tabular}

\subsubsection{Decontamination Swipes}

Concurrent with the efforts described in Section 3.3.6, an opportunity arose to collect simulated environmental swipe samples during a decontamination event. A piece of experimental equipment that had been exposed to volatilized depleted $\mathrm{UO}_{2}$ was undergoing decontamination. Two swipes were collected during the job by rubbing the cotton on the contaminated surfaces. These swipes were then counted in a DABRAS swipe counter in the $100-\mathrm{cm}^{2}$ counting tray. The net activities for the two swipes were $125.20 \pm 30.45 \mathrm{dpm}$ and $499.52 \pm 59.66 \mathrm{dpm}$, correlating to a total depleted $U$ content of $0.140 \pm 0.03 \mathrm{mg}$ and $0.560 \pm 0.07 \mathrm{mg}$, respectively. These swipes were then analyzed with the Olympus handheld XRF by slowly rastering the device across the surface of the swipe and watching the output; when an increase in count rate was noticed, the unit was stopped and a full scan was collected. In this fashion, hot spots on the swipes were identified that contained local U concentrations 30-60 times higher (point 2) than the average areal concentration of $5.6 \mu \mathrm{g} / \mathrm{cm}^{2}$ (Figure 13). 


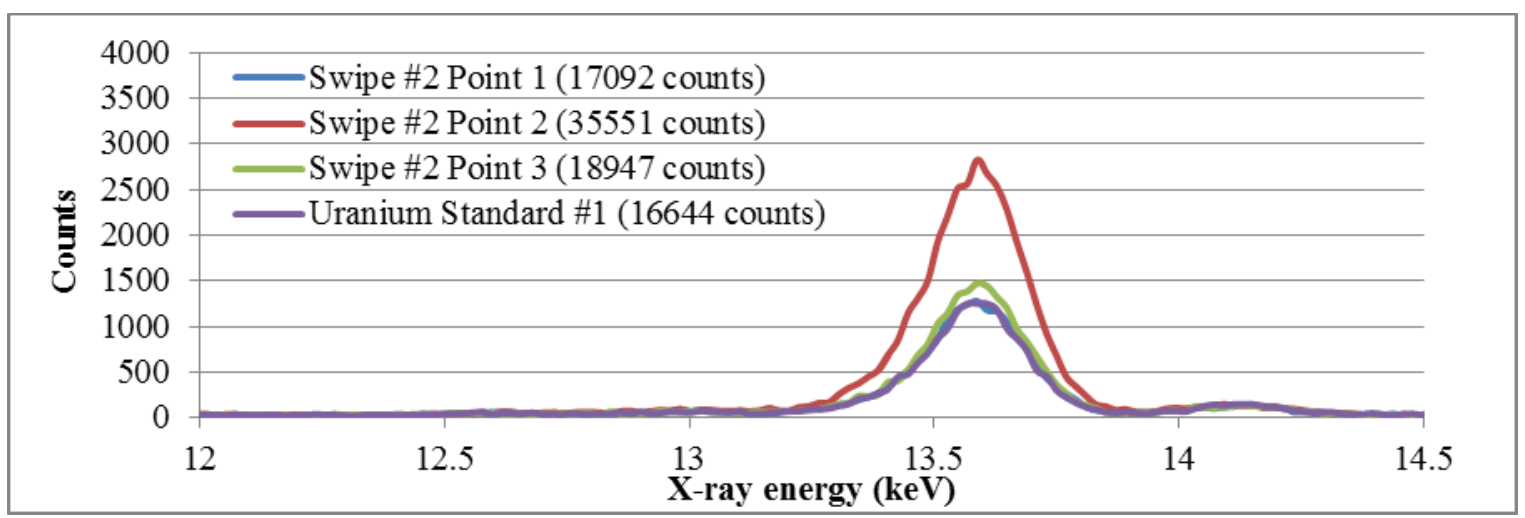

Figure 13-XRF results from decontamination swipes. For each graph, the integrated peak area is listed in the legend parenthetically. For reference, $\mathrm{U}$ standard \#1 has an areal concentration of $150 \mu \mathrm{g} / \mathrm{cm}^{2}$.

\subsubsection{Conclusions}

The handheld XRF unit can be used to determine low-level (ppm) U and Pu local concentrations on cotton swipes through plastic bags. This technique could be used to both identify interesting swipes and localize, roughly, areas with higher concentrations. The technique may also be able to detect small contributions from $\mathrm{Ca}$, though additional work will be required to confirm this.

\subsection{NEUTRON ACTIVATION ANALYSIS}

\subsubsection{Setup}

All samples were irradiated and analyzed at the University of Wisconsin Nuclear Reactor (UWNR). The UWNR is a 1-MW, open pool-type reactor, fueled with TRIGA low-enriched U with pulsing capabilities. The maximum fast and thermal neutron fluxes at $1 \mathrm{MW}$ are $3.0 \times 10^{13} \mathrm{n} \cdot \mathrm{cm}^{-2} \mathrm{~s}^{-1}$ and $3.2 \times 10^{13} \mathrm{n} \cdot \mathrm{cm}^{-2} \mathrm{~s}^{-1}$, respectively. The UWNR is equipped with several irradiation facilities, which include three hydraulic irradiation facilities, four beam ports, one thermal column, and a pneumatic transfer system. The irradiations performed during this project utilized the pneumatic transfer system and the hydraulic irradiation facilities located in core grid positions C8 and E8 ("whale tubes" C8 and E8), as depicted in Figure 14. The NAA program at the facility utilizes two high-purity germanium (HPGe) spectrometers with integrated automatic sample transfer system for high throughput and rapid irradiation and analysis. All samples were counted on a GEM-40190-P HPGe spectrometer (Serial \#31-TP20602A, South detector). The detector is coupled to a desktop computer-based PGT System 8000 multichannel analyzer, and analysis was performed by the UWNR-compiled program NAACalc version 1.41. 


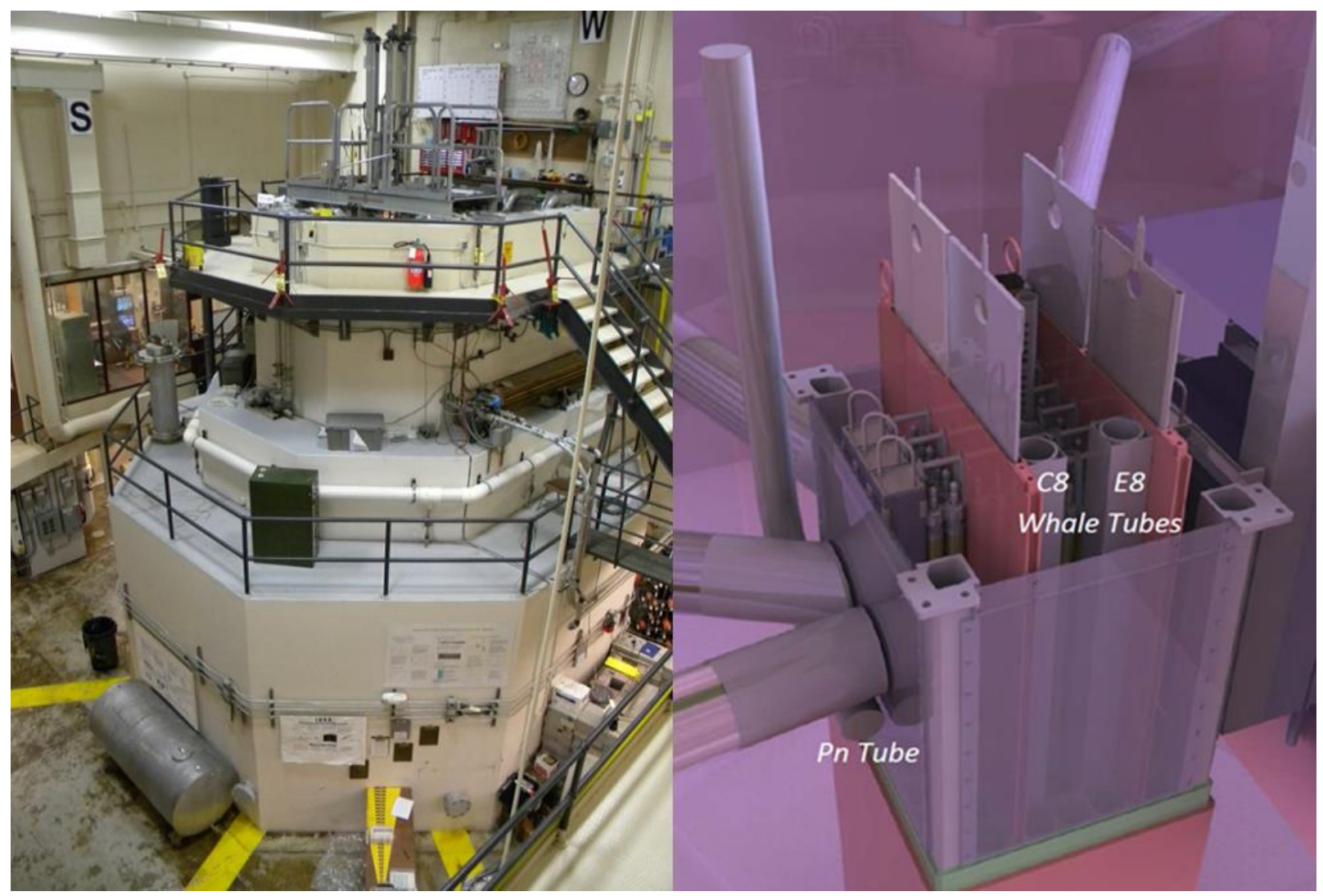

Figure 14-The UW Research reactor. Left, the reactor structure; right, diagram of irradiation tubes/ports in the reactor (Pn Tube = pneumatic transfer system). Photos courtesy of the University of Wisconsin Nuclear Reactor Laboratory.

\subsubsection{NAA Sensitivity Analysis}

The initial phase of the project was to conduct a sensitivity analysis of a blank wipe/bag combination sample. From this analysis, the minimum detectable concentration for elements suitable for NAA could be determined based on the possible interference photons present from the cotton wipe and polyethylene bag. The bag and swipe were also examined for any physical degradation.

The sample (ORNL-1) was inserted into a flip-top polyvial and sealed by friction welding. A standard sample was also prepared in a similar manner. The standard sample contained $299.1 \mathrm{mg}$ of Canadian Reference Standard CRS04, CAH soil.

On March 24, 2015, the sample and standard were irradiated for 2 hours in whale tube E8. The sample had a significant amount of sodium, which is a common contaminant that creates ${ }^{24} \mathrm{Na}$ when bombarded with neutrons. There was so much ${ }^{24} \mathrm{Na}$, which emits gamma rays that overload the HPGe detector, that the samples could not be counted until the ${ }^{24} \mathrm{Na}$ decayed. Beginning 7 days, 22 hours, and 45 minutes after irradiation ended, each vial was counted for 3,600 seconds at $0 \mathrm{~cm}$ on the vertical axis of the HPGe spectrometer. Fluxes were calculated 
based on the iron content of the standard and determined to be $1.464 \times 10^{13} \mathrm{n} \cdot \mathrm{cm}^{-2} \mathrm{~s}^{-1}$. Therefore, the sample was subject to a total thermal neutron fluence of $1.054 \times 10^{17} \mathrm{n} \cdot \mathrm{cm}^{-2} \mathrm{~s}^{-1}$.

Following the sensitivity analysis, the sample was subject to a visual inspection. It was observed that the inner bag had become brittle during the irradiation and that the bag had cracked. The physical integrity of the bag must be maintained for the purposes of this project.

\subsubsection{Fluence Analysis}

Subsequently, on July 28, 2015, three blank wipe/bag samples were packaged and irradiated for varying times to assess the irradiation-induced embrittlement of the bag. Sample ORNL-3a was irradiated in whale tube C8 for 15 minutes. The sample was subject to a thermal flux of $7.610 \times 10^{12} \mathrm{n} \cdot \mathrm{cm}^{-2} \mathrm{~s}^{-1}$ for a total thermal fluence of $6.849 \times 10^{15} \mathrm{n} \cdot \mathrm{cm}^{-2} \mathrm{~s}^{-1}$. Sample ORNL$3 \mathrm{~b}$ was irradiated in the same irradiation position for 30 minutes. The sample was subject to a total thermal fluence of $1.370 \times 10^{16} \mathrm{n} \cdot \mathrm{cm}^{-2} \mathrm{~s}^{-1}$. Finally sample ORNL-3c was irradiated in the same irradiation position for 60 minutes. The sample was subject to a total thermal fluence of $2.740 \times 10^{16} \mathrm{n} \cdot \mathrm{cm}^{-2} \mathrm{~s}^{-1}$. Following irradiation, the samples were inspected for physical integrity. The bags remained pliable and showed no sign of cracking. It was concluded that the bags could acquire a maximum fluence of $2.740 \times 10^{16} \mathrm{n} \cdot \mathrm{cm}^{-2} \mathrm{~s}^{-1}$, equivalent to 1 hour of irradiation in whale tube C8.

\subsubsection{Depleted Uranium Detectability Analysis}

Oak Ridge provided swipes that had known masses of specific elements added to the wipe. For the U detectability test, the following masses of DU were added to swipes and sealed in the zipper type bags: $10 \mu \mathrm{g}, 1 \mu \mathrm{g}, 100 \mathrm{ng}$, and $10 \mathrm{ng}$. The detection of $\mathrm{U}$ relies on the absorption of a thermal neutron in ${ }^{238} \mathrm{U}$ to produce ${ }^{239} \mathrm{U}$. This intermediate isotope beta decays to ${ }^{239} \mathrm{~Np}$ and emits several gamma photons (with energies of $99.5 \mathrm{keV}, 103.7 \mathrm{keV}, 106.4 \mathrm{keV}$, $228.1 \mathrm{keV}$, and $277.9 \mathrm{keV}$ ), making it easy to detect. Therefore, by observing the presence of ${ }^{239} \mathrm{~Np}$, the presence of ${ }^{238} \mathrm{U}$ is confirmed.

In order to maximize the sensitivity for the detection of the element, it is desirable to irradiate the sample for the greatest fluence possible until the saturated activity is reached. However, to use NAA as a pre-screening tool, it is important to minimize the amount of fission products produced without impacting sensitivity. The amount of irradiation time was minimized, which would still allow for element detection but limit fission products. On August 4, 2015, the DU samples were irradiated at $1 \mathrm{MW}$ in whale tube $\mathrm{C} 8$, as detailed in Table 8.

Each sample was subsequently counted at $0 \mathrm{~cm}$ on the vertical axis of the same GEM40190-P HPGe spectrometer, as shown in Figure 15. The count times and decay time following irradiations varied as detailed in Table 9; the count data is based on the 277.6-keV photon, as this photon has a reasonable yield $(14.4 \%)$ and negligible interference from other photon peaks. Figure 16 depicts results from the multichannel analyzer, focusing on the range from $200 \mathrm{keV}$ to $300 \mathrm{keV}$. As can be seen, ${ }^{239} \mathrm{~Np}$ is clearly detectable. It should be noted that no attempt to 
Table 8-Depleted uranium swipe irradiation data.

\begin{tabular}{cccccc}
\hline Sample ID & DU Mass & $\begin{array}{c}\text { Irradiation } \\
\text { Start Time }\end{array}$ & $\begin{array}{c}\text { Irradiation } \\
\text { End Time }\end{array}$ & $\begin{array}{c}\text { Total } \\
\text { Time (min) }\end{array}$ & Total Fluence \\
\hline ORNL-DUa & $10 \mu \mathrm{g}$ & $10: 18 \mathrm{AM}$ & $10: 23 \mathrm{AM}$ & 5 & $2.283 \times 10^{15} \mathrm{n} \cdot \mathrm{cm}^{-2} \mathrm{~s}^{-1}$ \\
ORNL-DUb & $1 \mu \mathrm{g}$ & $10: 37 \mathrm{AM}$ & $10: 52 \mathrm{AM}$ & 15 & $6.849 \times 10^{15} \mathrm{n} \cdot \mathrm{cm}^{-2} \mathrm{~s}^{-1}$ \\
ORNL-DUc & $100 \mathrm{ng}$ & $11: 10 \mathrm{AM}$ & $11: 25 \mathrm{AM}$ & 15 & $6.849 \times 10^{15} \mathrm{n} \cdot \mathrm{cm}^{-2} \mathrm{~s}^{-1}$ \\
ORNL-DUd & $10 \mathrm{ng}$ & $11: 42 \mathrm{AM}$ & $12: 12 \mathrm{PM}$ & 30 & $1.370 \times 10^{16} \mathrm{n} \cdot \mathrm{cm}^{-2} \mathrm{~s}^{-1}$ \\
\hline
\end{tabular}

quantify the activity was made, but rather just detect the presence of $U$ and therefore no efficiency was applied to the count rate data found in Table 9.

\subsubsection{Magnesium Detectability Analysis}

The $\mathrm{Mg}$ detectability analysis was conducted on August 6, 2015, and relied upon the reaction ${ }^{26} \mathrm{Mg}(\mathrm{n}, \gamma){ }^{27} \mathrm{Mg}$. With a 9.45-minute half-life, ${ }^{27} \mathrm{Mg}$ samples must be counted relatively soon following irradiation. Therefore, the Mg samples were irradiated in the pneumatic transfer system for 30 seconds at $1 \mathrm{MW}$, subjecting the samples to a fluence of $8.700 \times 10^{13} \mathrm{n} \cdot \mathrm{cm}^{-2} \mathrm{~s}^{-1}$. Each sample was counted at $0 \mathrm{~cm}$ on the vertical axis of the same GEM-40190-P HPGe spectrometer following a constant decay time of 5 minutes.

The results of the $\mathrm{Mg}$ analysis were inconclusive. A significant quantity of $\mathrm{Al}$ was detected in the sample by the presence of the ${ }^{28} \mathrm{Al} 1,779-\mathrm{keV}$

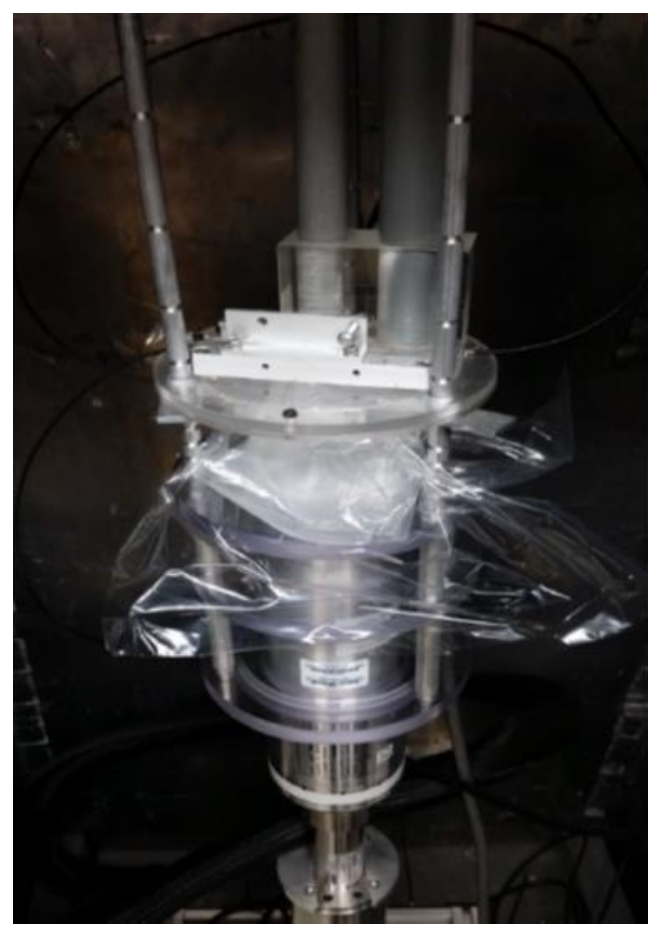

Figure 15-HPGe spectrometer counting configuration at $\mathrm{UW}$. photon. The origin of the $\mathrm{Al}$ is unknown; it may be a constituent of the wipe or the plastic bag, or it may result from $\mathrm{Mg}$ deposition. Furthermore, the ${ }^{27} \mathrm{Al}(\mathrm{n}, \mathrm{p})^{27} \mathrm{Mg}$ reaction co-produces ${ }^{27} \mathrm{Mg}$. The signals from the two $\mathrm{Al}$ isotopes indicate that the ${ }^{27} \mathrm{Mg}$ signal is dominated by the presence of Al.

\subsubsection{Calcium Detectability Analysis}

The Ca detectability analysis was conducted on August 6, 2015, and relied upon the reaction ${ }^{46} \mathrm{Ca}(\mathrm{n}, \gamma){ }^{47} \mathrm{Ca}$, with ${ }^{47} \mathrm{Ca}$ having a 4.5 -day half-life and emitting a $1,297-\mathrm{keV}$ photon. The sensitivity for Ca detection is very low, as the natural abundance of ${ }^{46} \mathrm{Ca}$ is $0.004 \%$. Elemental $\mathrm{Ca}$ is $96.94 \%{ }^{40} \mathrm{Ca}$, which activates to ${ }^{41} \mathrm{Ca}$ but does not emit any gamma rays. 
Table 9-Depleted uranium count data.

\begin{tabular}{cccccc}
\hline Sample ID & $\begin{array}{c}\text { DU } \\
\text { Mass }\end{array}$ & $\begin{array}{c}\text { Decay Time } \\
\text { (days) }\end{array}$ & $\begin{array}{c}\text { Count Time } \\
\text { (sec) }\end{array}$ & $\begin{array}{c}\text { Net Integral Counts in } \\
\text { 277keV Peak }\end{array}$ & $\begin{array}{c}\text { Calculated Count } \\
\text { Rate (cps) }\end{array}$ \\
\hline ORNL-DUa & $10 \mu \mathrm{g}$ & 6.0799 & 900 & 5,154 & 5.727 \\
ORNL-DUb & $1 \mu \mathrm{gg}$ & 6.0743 & 900 & 812 & 0.902 \\
ORNL-DUc & $100 \mathrm{ng}$ & 6.0646 & 3,600 & 687 & 0.191 \\
ORNL-DUd & $10 \mathrm{ng}$ & 6.0806 & 3,600 & 113 & 0.031 \\
\hline
\end{tabular}

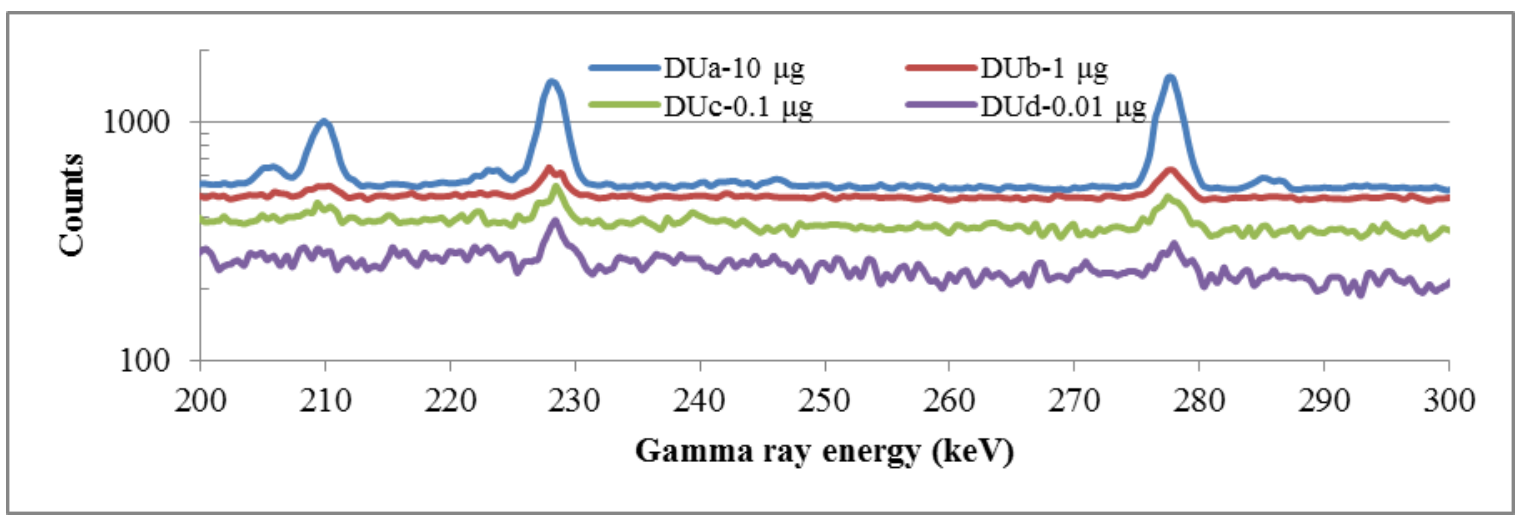

Figure 16-Delayed gamma ray spectroscopy for uranium samples. The spectra have been shifted along the ordinate axis for clarity.

The samples were irradiated for 30 minutes at $1 \mathrm{MW}$ in whale tube $\mathrm{C} 8$ for a fluence of $1.370 \times 10^{16} \mathrm{n} \cdot \mathrm{cm}^{-2} \mathrm{~s}^{-1}$. Each sample was counted at $0 \mathrm{~cm}$ on the vertical axis of the same GEM40190-P HPGe spectrometer. The count times and decay time following irradiations varied as detailed in Table 10. Figure 17 depicts the results from the multichannel analyzer, focusing on the range from $1,250 \mathrm{keV}$ to $1,350 \mathrm{keV}$. As can be seen, ${ }^{47} \mathrm{Ca}$ is clearly detectable in the $10-\mu \mathrm{g}$ and $1-\mu \mathrm{g}$ samples via the gamma photon at 1,297 $\mathrm{keV}$. Due to excessively long count times ( 8 hours for the $1-\mu \mathrm{g}$ sample), it was determined to be impractical to evaluate the remaining samples. It should be noted that no attempt to quantify the activity was made, but rather just detect the presence of $\mathrm{Ca}$ and therefore no efficiency was applied to the count rate data in Table 10. Additionally, it should be noted there was no significant (order of magnitude) reduction in the observed count rate. The significance of this fact has not been evaluated.

\subsubsection{Conclusions}

NAA is a viable technique for pre-screening IAEA swipes. NAA successfully identified $\mathrm{U}$ and $\mathrm{Ca}$; $\mathrm{Al}$ interferences did not allow for a successful $\mathrm{Mg}$ measurement. Now that the principle has been proven, further optimizations and determining elemental interferences must be the next step. A full parametric study of potential contaminants is necessary to determine if any detrimental effects (i.e., ${ }^{24} \mathrm{Na}$ and $\mathrm{Al}$ ) will negatively impact NAA as a pre-screening tool. Enrichment estimates may also be possible using NAA, which would make NAA a powerful prescreening tool. 
Table 10-Calcium count data.

\begin{tabular}{ccccc}
\hline $\begin{array}{c}\text { Sample } \\
\text { Mass }\end{array}$ & $\begin{array}{c}\text { Decay Time } \\
\text { (days) }\end{array}$ & $\begin{array}{c}\text { Count Time } \\
\text { (sec) }\end{array}$ & $\begin{array}{c}\text { Net Integral Counts in } \\
\mathbf{1 , 2 9 7 - k e V ~ P e a k ~ ( c o u n t s ) ~}\end{array}$ & $\begin{array}{c}\text { Calculated Count } \\
\text { Rate(cps) }\end{array}$ \\
\hline $10 \mu \mathrm{g}$ & 4.8882 & 14,400 & 412 & 0.0286 \\
$1 \mu \mathrm{g}$ & 5.0847 & 28,800 & 711 & 0.0247 \\
\hline
\end{tabular}

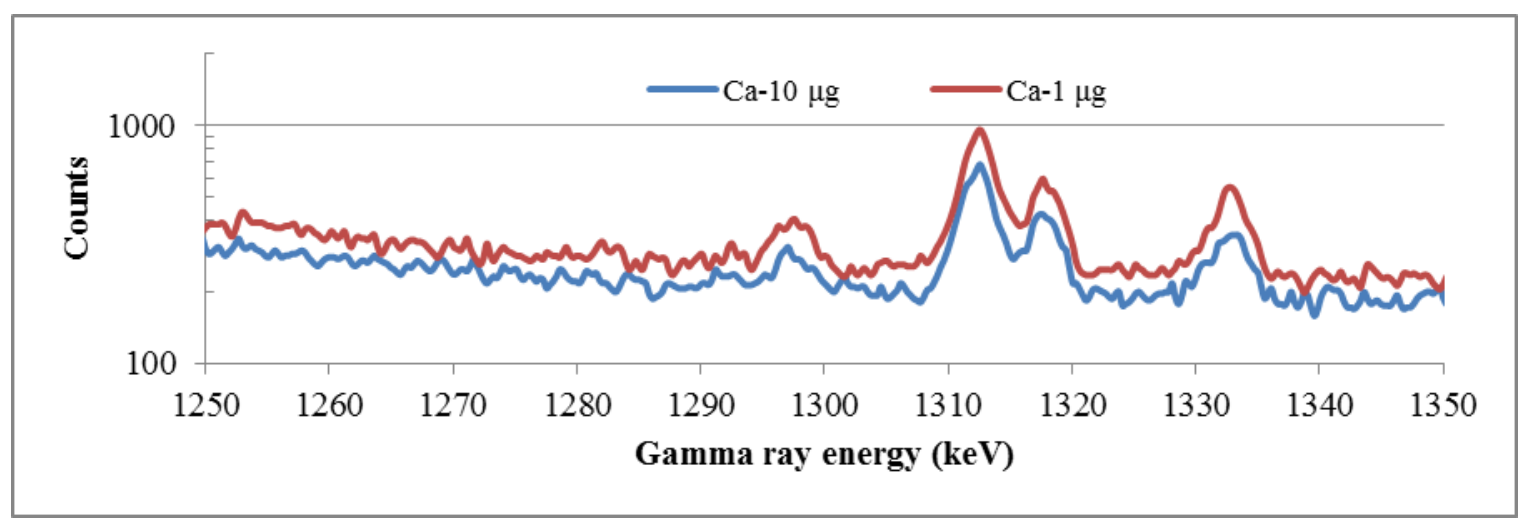

Figure 17-Delayed gamma ray peak due to Ca-47. The spectra have been shifted along the ordinate axis for clarity.

Enrichment measurements are possible by irradiating the samples and immediately counting delayed neutrons to estimate the ${ }^{235} \mathrm{U}$ content. The sample would then be gamma counted (using traditional NAA techniques) for ${ }^{238} \mathrm{U}$ content. These techniques are currently employed at the High Flux Isotope Reactor, but the small sample rabbit size makes it impractical to use for pre-screening swipes. The feasibility of an alternate location (i.e., UWNR) should be investigated.

\subsection{HANDHELD RAMAN SPECTROSCOPY}

\subsubsection{Setup}

The system utilized was a Kaiser Optical Systems Raman RXN1; the equipment was already on-site at Oak Ridge, and a non-contact probe was acquired for this work. Using an onsite system was essential, as the purchase of a new system for this project would have far exceeded the FY15 budget. Unfortunately, the system was designed for excitation using 532-nm laser light, which resulted in a considerable amount of background fluorescence from the swipe material. An example of this background is seen in Figure 18. This type of background can be seen when utilizing shorter wavelength excitation sources, and is generally attenuated by using longer wavelengths for Raman purposes. 
Swipe Background

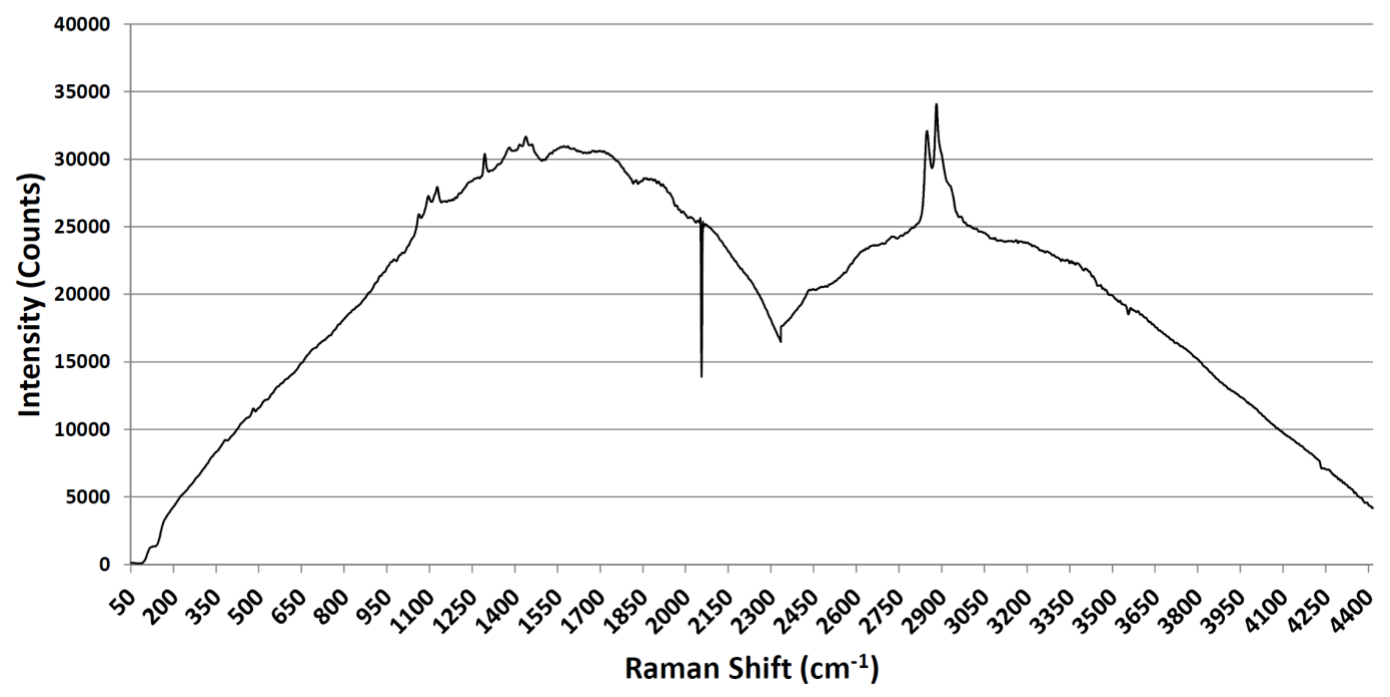

Figure 18 - Raman scattering. Image obtained using 532-nm excitation. The spectrum is substantially obscured by the fluorescence background present in the swipe material.

\subsubsection{Analysis}

While the full suite of swipes were examined using this system, the background observed in Figure 18 is representative of the signal obtained with each sample, with the exception of uranyl nitrate. The uranyl nitrate present in that swipe appeared to attenuate the background somewhat and allowed for the identification of peaks consistent with the target material. A representative Raman spectrum obtained from uranyl nitrate on a swipe is shown in Figure 19. Estimated assignments for each of the peaks observed in this spectrum are outlined in Table 11.

In the obtained spectrum, the uranyl symmetric stretch was clearly observed at $869 \mathrm{~cm}^{-1}$, and the $\mathrm{NO}_{3}{ }^{-}$symmetric band was also observed at $1,035 \mathrm{~cm}^{-1}$; however, the nitrate band was partially obscured by scattering from the swipe material. Although the data obtained using this approach to Raman analysis was inconclusive, some information can be gleaned from this work:

- Raman analysis of samples contained on swipe material should be acquired using longerwavelength excitation, such as $785 \mathrm{~nm}$ or 1,064 nm. Both wavelengths are common excitation sources for Raman spectroscopy; however, this should be investigated using in-house systems either at Argonne or Oak Ridge before expanded use by the IAEA can be recommended.

- While a point-and-shoot approach to Raman spectroscopy may be feasible using the appropriate wavelength, there remains a high likelihood of encountering a heterogeneous distribution of particulates associated with materials of concern to the IAEA. For this reason, an approach that can ultimately raster scan the entirety of a swipe (such as confocal Raman micro-spectroscopy) is strongly recommended should the method 


\section{Uranyl Nitrate}

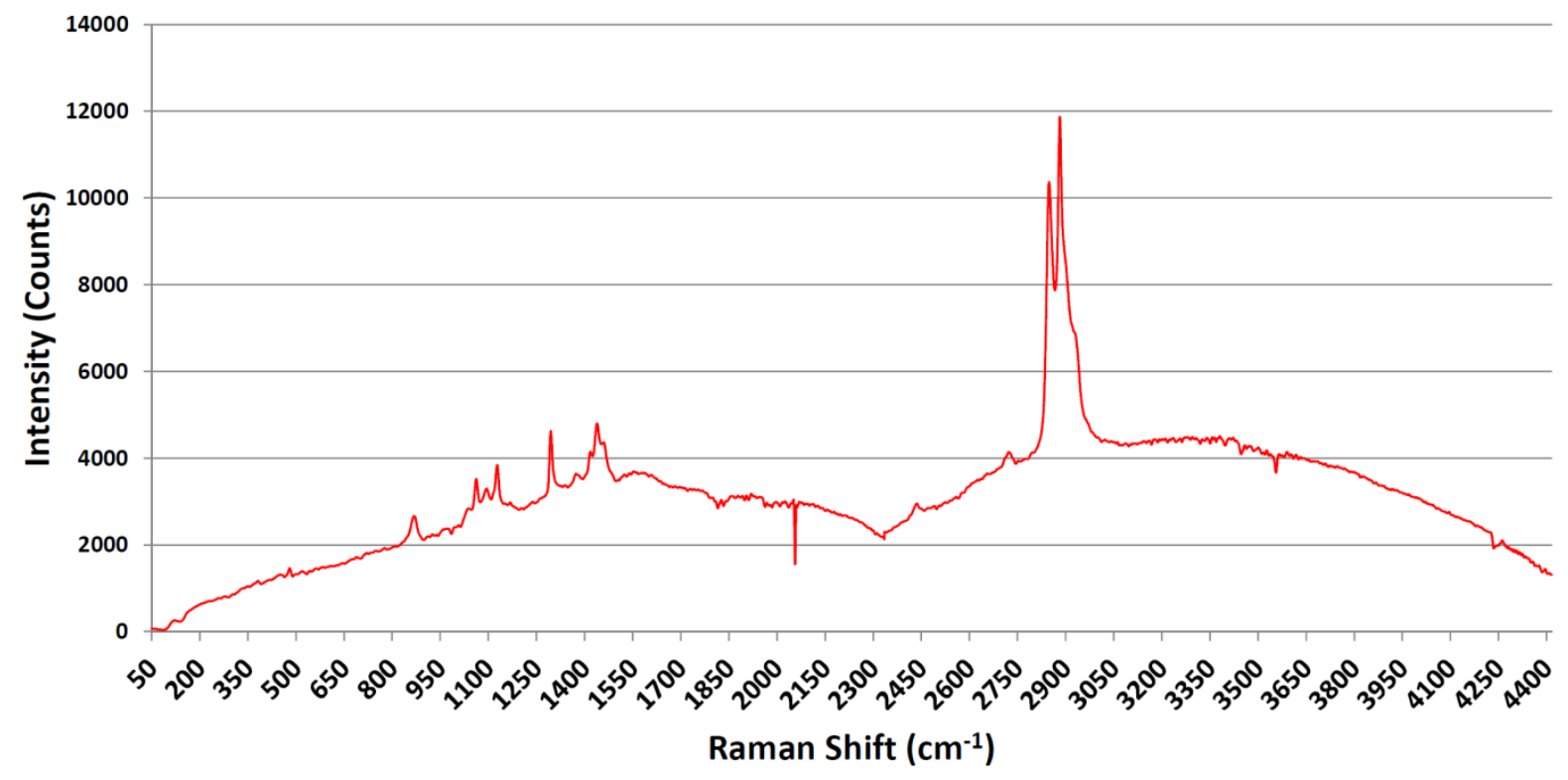

Figure 19-Raman spectrum of uranyl nitrate. The fluorescence background was attenuated by the presence of uranyl nitrate. However, the 532-nm excitation still creates a strong background.

Table 11-Peaks observed in uranyl nitrate Raman spectrum.

\begin{tabular}{cc}
\hline Peak Raman Shift & Estimated Peak/Material Assignment \\
\hline $869 \mathrm{~cm}^{-1}$ & $\mathrm{UO}^{2+}$ symmetric stretch (uranyl nitrate) \\
$1,035 \mathrm{~cm}^{-1}$ & $\mathrm{NO}_{3}^{-}$symmetric stretch (uranyl nitrate) \\
$1,059 \mathrm{~cm}^{-1}$ & $\mathrm{C}-\mathrm{O}$ stretch (swipe fiber) \\
$1,096 \mathrm{~cm}^{-1}$ & $\mathrm{COC}$ asymmetric stretch (swipe fiber) \\
$1,128 \mathrm{~cm}^{-1}$ & $\mathrm{COC}$ asymmetric stretch (swipe fiber) \\
$1,296 \mathrm{~cm}^{-1}$ & $\mathrm{CH}_{2}$ bending (swipe fiber) \\
$1,374 \mathrm{~cm}^{-1}$ & $\mathrm{CH}_{2}$ bending (swipe fiber) \\
$1,416 \mathrm{~cm}^{-1}$ & $\mathrm{CH}_{2}$ bending (swipe fiber) \\
$1,460 \mathrm{~cm}^{-1}$ & $\mathrm{CH}_{2}$ bending, COH bending (swipe fiber) \\
2,849 and $2,883 \mathrm{~cm}^{-1}$ & $\mathrm{C}-\mathrm{H}$ stretch (swipe fiber) \\
\hline
\end{tabular}

advance to application in pre-screening scenarios. Other specialized techniques may be evaluated in the future, but they are currently far beyond the scope of this study.

The Raman approach is certainly a feasible one; however, the use of readily available instrumentation at Oak Ridge limited the scope of this study. The results from this work show that point-and-shoot Raman spectroscopy using a 532-nm excitation source is infeasible for prioritization of swipes for destructive analysis. 


\subsection{CONFOCAL RAMAN MICROSCOPY}

\subsubsection{Setup}

The instrument used was a Renishaw inVia confocal Raman spectrometer. This instrument used a 300-mW, 785-nm laser source with Rayleigh line rejection edge filters, allowing measurements at better than $100 \mathrm{~cm}^{-1}$. This laser was focused though a trinocular Leica microscope mounted with $5 \times, 20 \times$, and $100 \times$ objective lenses. The microscope also has an integrated CMOS camera and a manual XY sample stage. The Raman scattered light is passed through a $250-\mathrm{mm}$ spectrograph and collected on a Peltier-cooled CCD array $(1,024 \times 256$ pixels $)$.

Blank samples were initially used to determine the optimal conditions for the analysis, particularly for reducing the contribution of fluorescence from the cotton swipe to the signal. For this reason, the lower-energy 785-nm IR laser was selected, which virtually eliminated broadband fluorescence from the cotton. During this analysis, it was discovered that the computer-driven autofocusing routine was having difficulty focusing through the double plastic bags. Therefore, for the proof of concept tests, we decided to remove the samples from their plastic bags. As the samples from the inter-comparison study could not be opened, additional samples were made for this test. It should be noted that the TBP swipe from Oak Ridge was inadvertently opened and analyzed. As this sample will not be analyzed by NWAL, the impact of this mistake is negligible. While the autofocus routine used could not reliably focus through the bags, the researcher could manually focus through the plastic bag, indicating that it may be possible to automate this functionality.

In reviewing the swipe materials that were sent, only the TBP and the U compounds would have Raman active transitions, reducing the analytical space. Therefore, using a blank swipe, a new U swipe was created by dotting $0.100 \mathrm{~mL}$ of a 0.25 -molar $(\sim 60 \mathrm{~g} / \mathrm{L}$ as $\mathrm{U})$ solution of uranyl nitrate on the cotton and allowing it to dry. This produced a sample similar to the uranyl nitrate swipe prepared by Oak Ridge.

\subsubsection{Analysis}

The microscope was centered on the U spot and spectra were taken with all three objective lenses and Raman scattering images were taken with the $20 \times$ and $100 \times$ objectives. A large number of peaks are present in the sample, mostly corresponding to the swipe material (i.e., C-C stretching). The relevant $\mathrm{U}$ signal is found at $870 \mathrm{~cm}^{-1}$, which corresponds to the uranium-oxygen symmetric stretch. The Raman intensity in the field of view would be proportional to the concentration of the analyte present; consequently, the signal intensity does not track linearly with the magnification. Therefore, if a large amount is present in an area and a more powerful objective lens is used, the relative ratio of analyte to background can shift and reduce the overall signal. 


\subsubsection{Results}

The U signal is visible with all objective lenses, as shown in Figure 20. It should be noted that the $20 \times$ lens had a higher signal than both the $100 \times$ and $5 \times$ lenses. This is consistent with the understanding that the relative $U$ concentration in the field of view is the diagnostic measurement occurring. Images were also collected at the $20 \times$ and $100 \times$ magnifications, with the $875-\mathrm{cm}^{-1}$ signal highlighted in blue (Figure 21).

Focusing on the $100 \times$ image (Figure $21 \mathrm{~B}$ ), the researcher noted that at this level, the instrument was essentially focused on a single fiber of the swipe. This is confirmed by the scale of the fiber, on the order of $10 \mu \mathrm{m}$ to $20 \mu \mathrm{m}$ wide. This resolution is also consistent for particulate matter that could be collected on a swipe. A calculation of the amount of $U$ present in the field of view, based on the Raman image and the estimated average areal density of $U$, indicates that the system was sensitive to tens to hundreds of nanograms of $U$. This finding has

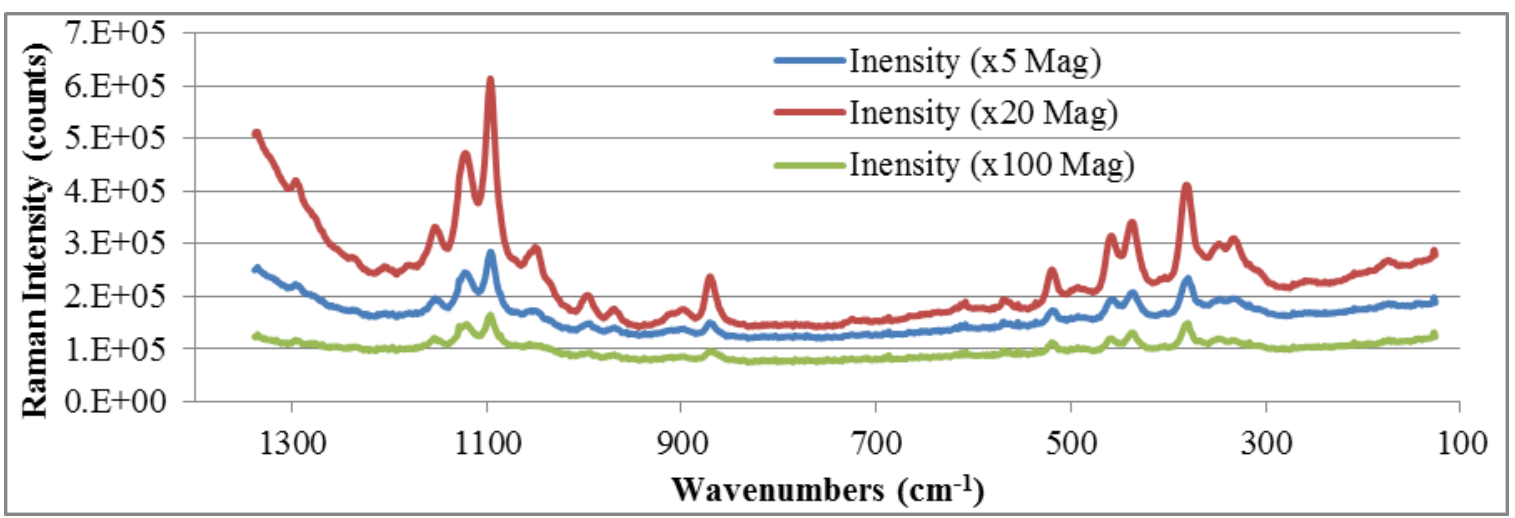

Figure 20 - Raman spectra of uranyl nitrate swipe. This figure shows the clear stretch at $875 \mathrm{~cm}^{-1}$, corresponding to the uranyl symmetric stretch.

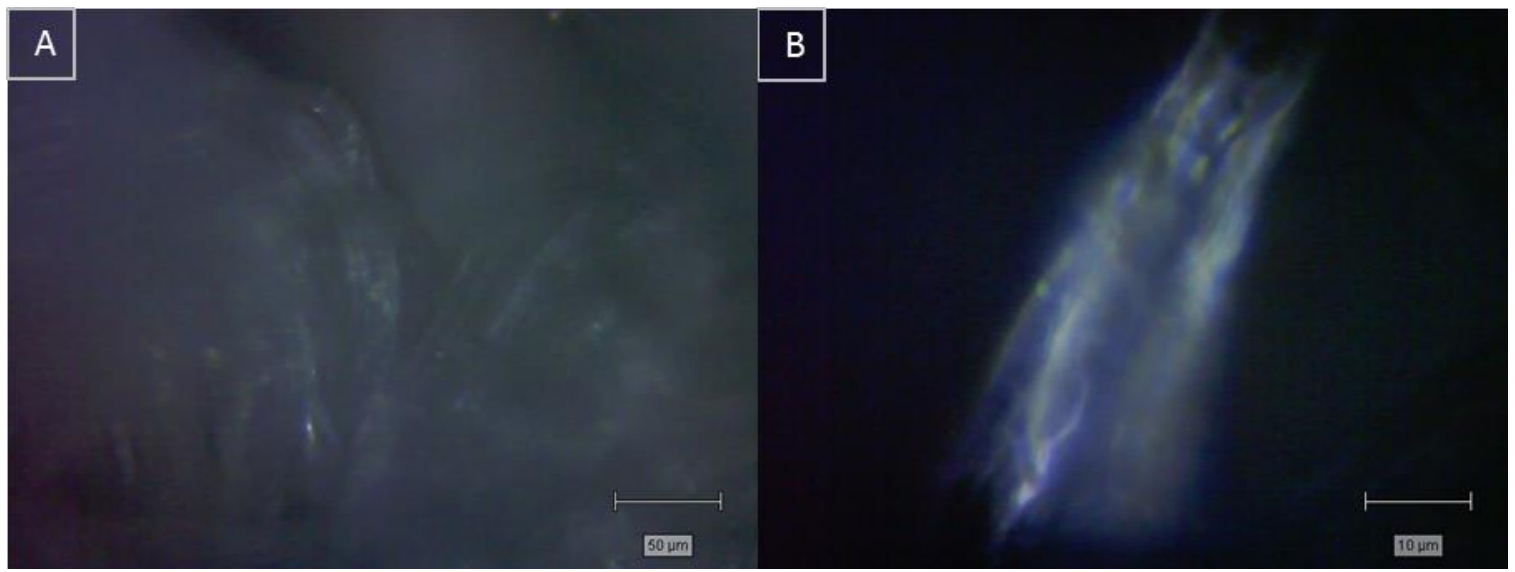

Figure 21-Confocal Raman Images. (A) An image of the U swipe at the $20 \times$ level, showing large amounts of diffuse signal. (B) An image of a single cotton fiber at $100 \times$ magnification, containing about $20 \mathrm{ng}$ of $\mathrm{U}$. The areal density in both images is assumed to be constant. 
two caveats. First, the actual areal density in the field of view could be locally higher, skewing the results. Second, the area imaged is approximately $4 \times 10^{-5}$ percent of the total swipe area; a complete image of the swipe at this resolution would require over $2.6 \times 10^{6}$ individual scans.

Because of these factors, confocal Raman is not a good candidate for bulk analysis with the current setup at Argonne. However, given an area to investigate, the system has the potential to localize and identify particulates on a swipe. Automated analysis routines could possibly use multiple objective lenses to find high local concentrations and identify particles that contain certain compounds. This technique could be used in conjunction with, or instead of, fission track analysis for localizing hot particles for further analysis.

\subsection{FLUORESCENCE MICROSCOPY}

\subsubsection{Setup}

Oak Ridge has a stereomicroscope on-site, which was upgraded with fluorescence capabilities for this work. Under normal circumstances, the field of view provided in images collected via microscopy is small, limiting the capability of viewing macro-scale objects in their entirety. The stereomicroscope used for this work employs a set of motorized stages controlled by a software interface. This system captures and stitches together multiple images while scanning the sample surface, providing macro-scale, high-resolution images of samples with large surface areas, such as that encountered when probing swipe material. Shown in Figure 22 are composite brightfield and fluorescence micrographs of a $25 \times 19-\mathrm{mm}$ region of a doublebagged blank swipe sample using this process. Each image is composed of 108 individual captures that are pieced together to form a large-scale view of the swipe surface. The system is capable of imaging regions $75 \times 50 \mathrm{~mm}$ in size, and others are available that may expand this scale to $150 \times 100 \mathrm{~mm}$ or larger, ultimately allowing for the examination of an entire swipe sample in a matter of minutes using this technique.

\subsubsection{Analysis}

For the examination of uranyl species, the $10-\mu \mathrm{g}$ uranyl fluoride swipe was analyzed. A larger area was scanned for these swipes, and representative images collected through the swipe packaging are shown in Figure 22. In this case, the brightfield scan does not display much information; however, the fluorescence scan shows an outline of the deposition area, potentially due to uranyl fluoride fluorescence. While this information does show some promise with the rapid analysis of swipe material for target species, uranyl fluoride was not the only sample to provide such a result. In the analysis of lithium hydroxide (which was deposited in an identical manner), a similar but more attenuated signal was observed, leaving questions as to whether it was the material or the solution that produced this signal. Example composite images of this solution are shown in Figure 23. While this could constitute a false positive in an operational sense, the technique is only envisioned to be a pre-screening method and still may be viable for 


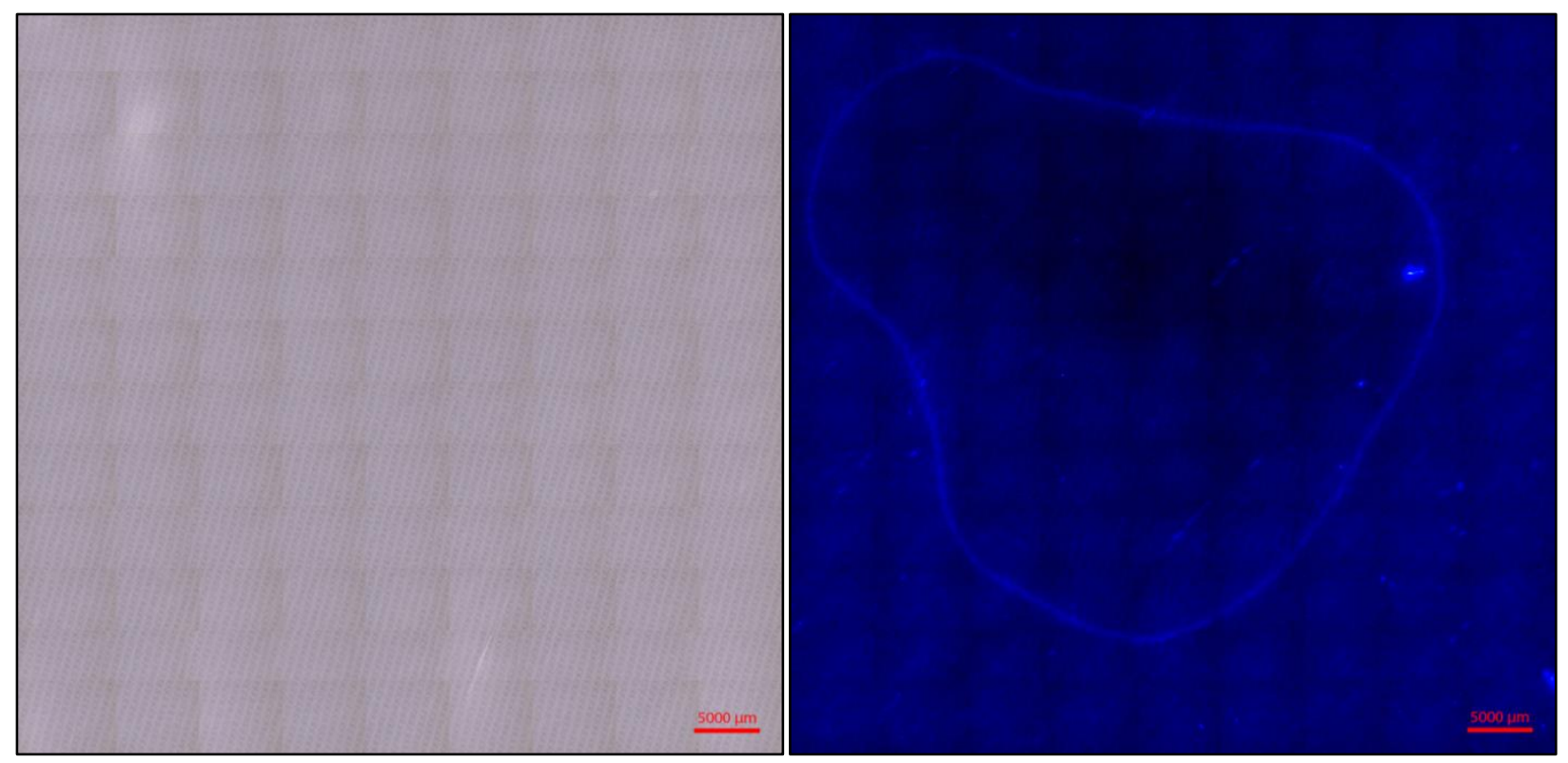

Figure 22-Uranyl fluoride swipe imaged using brightfield and fluorescence microscopy. At left is a composite brightfield image of the swipe. At right is the fluorescence channel of the same area, showing an outline of the deposition area. Dimensions are $55 \times 55 \mathrm{~mm}$, and scale bars represent $5 \mathrm{~mm}$ in both images.
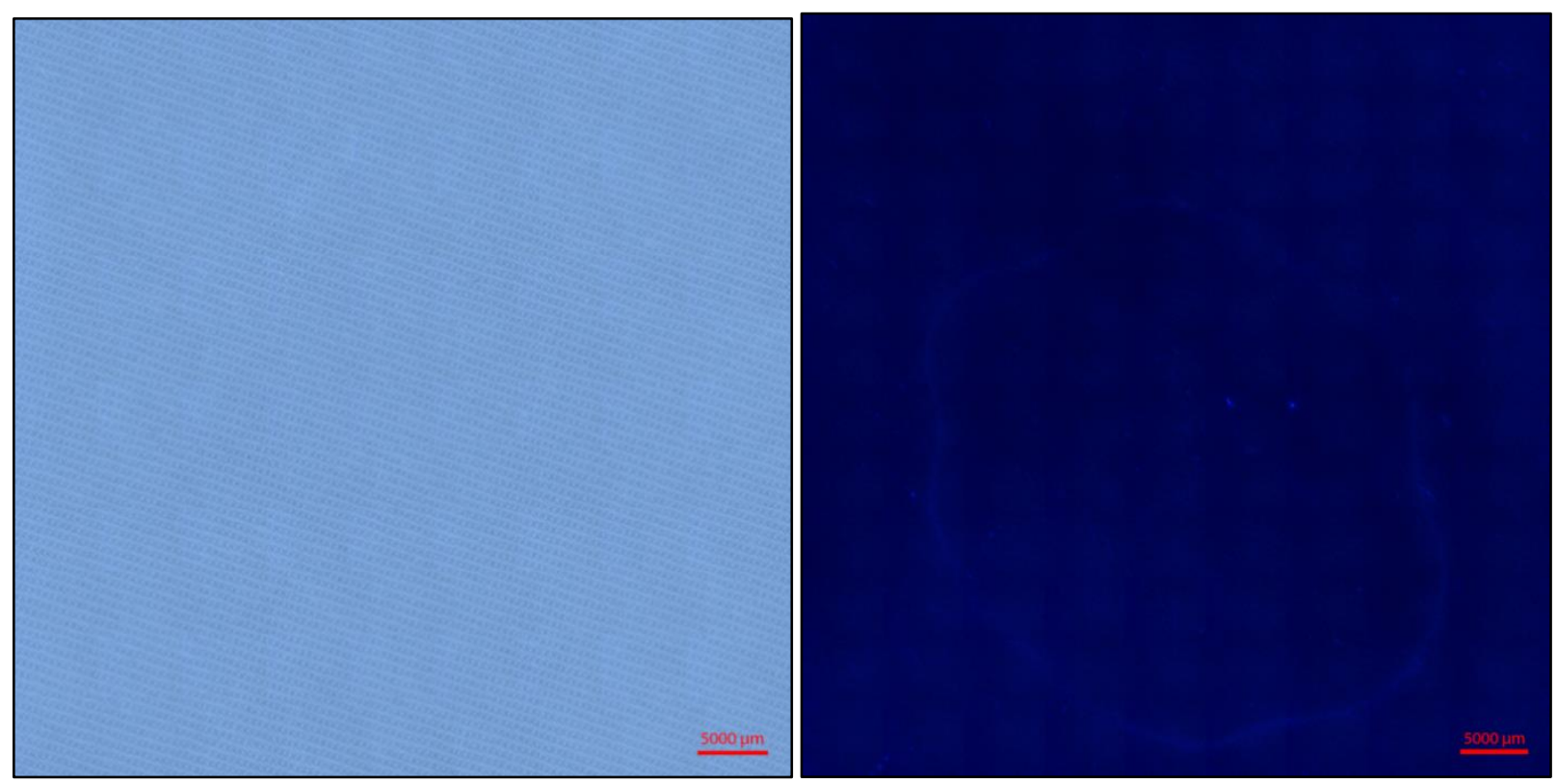

Figure 23-Lithium hydroxide-doped swipe imaged using brightfield and fluorescence microscopy. At left is a composite brightfield image of the swipe. At right is the fluorescence channel of the same area, with an attenuated outline of the deposition area. Dimensions are $55 \times 55 \mathrm{~mm}$, and scale bars represent $5 \mathrm{~mm}$ in both images. 
pre-screening purposes, as it would merely prioritize swipes with potential fluorescence interference.

In contrast with uranyl fluoride, altering the counter-ion to nitrate completely removes the emission profile from the fluorescence optics employed. When viewing these images under the microscope, the uranyl nitrate showed no observable fluorescence. Whether or not this was due to instrument light-gathering limitations (the microscope at Oak Ridge is not equipped with a low-light camera) or due to inappropriate fluorescence optics is unclear. It is known that the uranyl counter-ion will have an effect on the excitation/emission profile, but without performing a parametric investigation by exchanging multiple filters, the capability of measuring numerous uranyl species with this technique remains unclear.

The issue associated with this particular system is that it is manufactured to be a plugand-play device and does not easily permit modification of the optics to test custom optical components. Several stock fluorescence cubes were examined for this project; however, the process of performing this type of analysis would be iterative in nature and require fine-tuning of optical components to decrease background fluorescence and interference, while maximizing the signal obtainable from uranyl species. While the microscope on-site at Oak Ridge is very userfriendly, performing this iterative process with such a system would require the purchase of numerous complete filter cubes. Because each cube would be custom-tailored, the iterative process for determining an appropriate excitation, dichroic, and emission filter would have been prohibitively expensive for this scope of work at Oak Ridge.

The goal of this work was to test the feasibility of fluorescence microscopy for prescreening purposes. Detection limits for fluorescence microscopy can reach the single-molecule level; however, the swipe material is known to be fluorescent - the initial goals of this work were to determine if the fluorescence of uranyl species could be differentiated from the swipe material.

\subsubsection{Results}

While the technique appears promising, it is strongly recommended that any further investigation be performed by an academic laboratory specializing in fluorescence microscopy. The costs would be drastically reduced, and individual parameters could be appropriately tested to determine if this method is truly feasible for prioritizing double-bagged swipes for destructive analysis. The manufacturer of the microscope at Oak Ridge is capable of building custom filter sets, and if the technique is found feasible, information on the specific optics to be used could be provided to build a filter cube tailored for uranyl fluoride, uranyl nitrate, or other fluorochromes of interest. 


\subsection{ATR INFRARED SPECTROSCOPY}

\subsubsection{Setup}

Due to the low absorption coefficient for the potential species in the IR region, it was theorized that a reflectance system may be able to collect a signal with a locally high concentration (particle or collection of particles), requiring a small point analysis rather than a large-area transmission analysis. While specular reflectance, diffuse reflectance, and other IR sampling techniques may have better potential signals, they were unavailable for testing under this scope of work. Therefore, emphasis was placed on testing available IR spectrometers that utilized an anvil ATR sample port. The utility of these spectrometers was debatable due to the short penetration depth of the IR beam past the ATR window, though they were included due to the negligible cost of testing.

Two ATR-IR systems from Thermo Scientific were used during this study: (1) Nicolet iS 10 FT-IR spectrometer and (2) Nicolet 6700 FT-IR. Both systems used diamond windows and deuterated triglycine sulfate detectors. A set of simulated swipes containing microgram to milligram quantities of cobalt were created (see Section 3.3.4). On the sample with the highest concentration, the cobalt presented as a visible smear with a pink color. This allowed high local concentrations of cobalt to be positioned on the sample anvil at concentrations where an observable signal would be expected. Cobalt has a relatively strong absorbance at about $1,390 \mathrm{~cm}^{-1}$ (Miller 1952). The polyethylene bags have IR absorbance peaks at approximately $750 \mathrm{~cm}^{-1}, 1,490 \mathrm{~cm}^{-1}, 2,910 \mathrm{~cm}^{-1}$, and $2,950 \mathrm{~cm}^{-1}$ (Shimazdu 2015). The cobalt was used as a cold surrogate prior to analysis of the round robin samples due to the potential to damage samples in the anvil.

\subsubsection{Results}

Upon initial testing with bagged cellulose samples containing cobalt, it became readily apparent that while the bag material did not pose a spectral interference, the sample had to be compressed significantly for the ATR port to function. This resulted in damage to the bag and the sample with a visible indentation observed. The integrity of the bag would then be put into question. Multiple engineering solutions were attempted to work around this issue, including providing a number of backing materials and weights to provide the required analytical surface. However, none of these efforts resulted in obvious cobalt or polyethylene absorption signals or even a consistent signal from location to location on the sample bags. At this point, we decided to focus additional effort on more promising techniques.

\subsection{INTER-COMPARISON STUDY}

Table 12 provides a comparison of what each analytical method was able to detect based upon the provided calibration swipes from Oak Ridge. No single analytical method was capable of detecting the analyte on every swipe, largely due to at least one swipe being out of the 
Table 12-Results of the inter-comparison study.

\begin{tabular}{|c|c|c|c|c|c|c|}
\hline Swipe & XRF & NAA & $\begin{array}{l}\text { Handheld } \\
\text { Raman }\end{array}$ & $\begin{array}{l}\text { Confocal } \\
\text { Raman }\end{array}$ & $\begin{array}{c}\text { Fluor. } \\
\text { Microscopy }\end{array}$ & $\begin{array}{c}\text { ATR-IR } \\
\text { Spectroscopy }\end{array}$ \\
\hline 99.9\% Deuterated water & $\mathrm{n} / \mathrm{a}$ & $\mathrm{n} / \mathrm{a}$ & & & $\mathrm{n} / \mathrm{a}$ & \\
\hline Uranyl nitrate & $x$ & Z & & Z & & \\
\hline Uranyl fluoride & & Z & $\mathrm{Y}$ & & $\mathrm{Y}$ & \\
\hline Lithium hydroxide & $\mathrm{n} / \mathrm{a}$ & $\mathrm{n} / \mathrm{a}$ & $\mathrm{n} / \mathrm{a}$ & $\mathrm{n} / \mathrm{a}$ & Y & $\mathrm{n} / \mathrm{a}$ \\
\hline Calcium nitrate & Y & Z & $\mathrm{n} / \mathrm{a}$ & $\mathrm{n} / \mathrm{a}$ & $\mathrm{n} / \mathrm{a}$ & $\mathrm{n} / \mathrm{a}$ \\
\hline Magnesium nitrate & $\mathrm{Y}$ & $\mathrm{Y}$ & $\mathrm{n} / \mathrm{a}$ & $\mathrm{n} / \mathrm{a}$ & $\mathrm{n} / \mathrm{a}$ & $\mathrm{n} / \mathrm{a}$ \\
\hline Tri-n-butyl phosphate & $\mathrm{n} / \mathrm{a}$ & $\mathrm{n} / \mathrm{a}$ & & & $\mathrm{n} / \mathrm{a}$ & \\
\hline
\end{tabular}

$X$ - Confirmed signal using round robin swipe; $Y$ - Potential signal using round robin swipe; $Z$ - Confirmed signal on nonround robin sample.

analytical range of each method. Some of the swipes were expected to be out of analytical range (i.e., deuterated water with XRF and NAA), and this was intentionally designed due to the breadth of testing each method so that all techniques, whether isotopic, elemental, or chemical, would have at least a couple of swipes within their top analytical ranges. With that being said, $\mathrm{XRF}$ and NAA were able to positively confirm or potentially confirm the most swipes provided in the calibration set.

Despite some caveats, as mentioned in the above discussion, we believe these two methods would be the most field deployable for future testing. Other methods, such as confocal Raman and fluorescence microscopy, were able to detect some analytes, but it was not feasible to detect the other analytes on the swipes without significant upgrades in research equipment (confocal Raman) or outsourcing to academia (fluorescence microscopy). And lastly, IR and handheld Raman did not successfully confirm any analyte in the calibration set. Although IR could be improved upon with a confocal microscope, this too would take additional research and instrumentation capabilities to move forward. 


\section{SUMMARY AND RECOMMENDATIONS}

Overall, Argonne and Oak Ridge evaluated six different analytical methods that had potential for pre-screening and prioritizing IAEA swipes. The analytical challenge for this project is that each analytical method had to measure analytes through a double plastic bag to maintain chain-of-custody considerations. No analytical technique was able to qualitatively and/or quantitatively identify each test compound. Some techniques, like XRF, were able to easily measure heavier elements like $\mathrm{Ca}$ and $\mathrm{U}$. But the handheld XRF was not able to measure any type of organic (TBP) or light-element compound $\left(\mathrm{D}_{2} \mathrm{O}\right)$. NAA was able to detect DU but was not able to detect $\mathrm{Mg}$ due to $\mathrm{Al}$ interferences. These two techniques were deemed to have the most promise for in-depth research without a significant amount of investment in purchasing new equipment or changing scope.

For the future, priorities on what type of chemical compounds are the most important to be pre-screened will have be established to determine what analytical method is best suited for measurement through a double plastic bag. For example, emphasis may be placed on specific detection of $\mathrm{Ca}$ and $\mathrm{Mg}$, which can indicate that a reduction process is taking place within a facility. That would allow us to strongly recommend using XRF based upon the results in this study. Or, emphasis may be placed upon detection of organics, in which case confocal Raman spectroscopy is likely the best analytical method. Alternatively, emphasis might be placed upon strict detection of $U$, in which NAA or possibly XRF is likely the best method to research further. Although this research is preliminary and far from a final conclusion, below are our recommendations for further in-depth testing based upon the results from this FY15 study.

\subsection{RECOMMEDNED TECHNIQUES FOR FURTHER RESEARCH}

\subsubsection{XRF}

While it was understood that the handheld XRF would not be able to measure $\mathrm{LiOH}$, $\mathrm{D}_{2} \mathrm{O}$, and potentially the fluoride anion of $\mathrm{UO}_{2} \mathrm{~F}_{2}$, the handheld XRF still provided very positive results for identifying important elemental compositions to infer chemical contributions to swipe samples. The main advantage for handheld XRF is the favorable measurement geometry and the ability to analyze through plastic bags with ease. The handheld XRF easily identified $U$ from the uranyl nitrate swipe. Though this was the highest-concentration sample, the performance made XRF stand out among the techniques evaluated. Additionally, XRF possibly detected small amounts of $\mathrm{Ca}$ on the swipe; this was unanticipated, as $\mathrm{Ca} \mathrm{K}-\alpha$ lines are not particularly sensitive in this region, especially using a handheld instrument. In addition to the Oak Ridge standard swipes, the handheld XRF was able to detect $\mathrm{U}$ and $\mathrm{Pu}$ at the tens of $\mu \mathrm{g} / \mathrm{cm}^{2}$ level. This is an important development, as the XRF spectrometers that are utilized currently by the NWAL are for cold non-radioactive elements only. These results would indicate a change to the way the instruments are used by analyzing swipes for their $\mathrm{U}$ or $\mathrm{Pu}$ content rather than relying solely upon traditional radio-analytical methods. This will be very useful for prioritizing swipes based upon $\mathrm{U}$ or $\mathrm{Pu}$ detection. 
These results make XRF promising for pre-screening swipes. The type of handheld instrument that was used specifically for this project is excellent for fast results but presents limitations due to the lack of vacuum or He purge to accurately measure the lighter elements that are of interest to IAEA inspectors. Handheld XRF instrumentation is available on the market and would remedy the issues with the current Argonne setup. The advantage of using the handheld instrument is that the area of detection is quite small (1 $\mathrm{mm}$ to $5 \mathrm{~mm}$ on average) compared to benchtop devices. It is important to note that small benchtop devices are able to measure the light elements in question with ease, since they are capable of holding the detector under vacuum or able to purge with He.

This small area measurement made with the handheld XRF allows for detection of trace amounts of $\mathrm{U}$ and $\mathrm{Pu}$. Some NWAL facilities utilize benchtop XRF instruments; the caveat is that the surface area of the measurement is the diameter of the smear, which increases the limits of detection for materials like $\mathrm{U}$ and $\mathrm{Pu}$. The smaller interrogation area decreases the limit of detection but would require multiple scans to completely analyze the swipe. The XRF technique should still be considered for future work; however, we recommend moving toward a more robust instrument (i.e., a benchtop instrument) capable of detecting light elements and possibly with a motorized sample stage.

\subsubsection{Neutron Activation Analysis}

The initial phase of the project was to conduct a sensitivity analysis of a blank wipe/bag combination sample. From this analysis, the minimum detectable concentration for elements suitable for NAA could be determined based on the possible interference photons present from the cotton wipe and polyethylene bag. The bag and swipe were also examined for any physical degradation.

NAA is a viable technique for pre-screening IAEA swipes. NAA successfully identified $\mathrm{U}$ and $\mathrm{Ca}$; $\mathrm{Al}$ interferences did not allow for a successful $\mathrm{Mg}$ measurement. Now that the principle has been proven, further optimizations and determination of elemental interferences must be the next step. A full parametric study of potential contaminants is necessary to determine if any detrimental effects (i.e., ${ }^{24} \mathrm{Na}$ and $\mathrm{Al}$ ) will negatively impact NAA as a pre-screening tool. Enrichment estimates may also be possible using NAA by comparing delayed neutron emissions to gamma emissions, which would make NAA a powerful pre-screening tool.

\subsection{PROMISING TECHNIQUES}

\subsubsection{Confocal Raman Microscopy}

The confocal Raman microscope is very promising technique to isolate and identify small particles of material. The instrument was able to successfully focus on a single fiber of the swipe bearing tens to hundreds of nanograms of $U$ and detect a distinct uranyl Raman signal. The advantage of the confocal Raman is that the confocal microscope can focus on the heterogeneous 
analyte deposits on the swipe, whereas the handheld instrument takes an average over the measurement area.

In the instrument's current configuration, the confocal Raman microscope is not a good candidate for bulk analysis. However, given an area to investigate, the system has the potential to localize and chemically identify particulates on a swipe. Automated analysis routines could possibly use multiple objective lenses to find high local concentrations and identify particles that contain certain compounds. Instruments for this purpose could be obtained for $\$ 150,000$ $\$ 250,000$; manufacturers routinely provide highly customized setups and equipment. In this capacity, confocal Raman is very promising as it could be used in conjunction with, or instead of, fission track analysis for localizing hot particles for further analysis.

\subsubsection{Fluorescence Microscopy}

Fluorescence microscopy, due to its highly senstive nature and high selectivity, was anticipated to produce strong U signals. After testing the Oak Ridge round robin swipes, it was clear that more research would be needed in order to opimize the technique's ability to prescreen swipes. The fluorescence scans show outlines of the deposition areas, potentially due to uranyl fluoride fluorescence or other materials in the cotton matrix. While this information does show some promise with the rapid analysis of swipe material for target species, uranyl fluoride was not the only sample to provide such a result. In the analysis of lithium hydroxide (which was deposited in an identical manner), a similar signal (although more attenuated) was observed, though Li should not have a fluorescent signal at all; this indicates that the fluorescence observed may be due to something other than the analyte. In contrast with uranyl fluoride, altering the counter-ion to nitrate completely removes the emission profile from the fluorescence optics employed. When viewing these images under the microscope, the uranyl nitrate showed no observable fluorescence. It is not clear whether this was due to instrument light-gathering limitations (the microscope at Oak Ridge is not equipped with a low-light camera) or due to inappropriate fluorescence optics. The uranyl counter-ion is known to have an effect on the excitation/emission profile, but without performing a parametric investigation exchanging multiple filters, the capability of measuring numerous uranyl species with this technique remains unclear.

While the technique clearly cannot be discarded as a potential method, it is strongly recommended that any further investigation be performed by an academic laboratory specializing in fluorescence microscopy. This will reduce costs drastically, and individual parameters could be appropriately tested to determine this method's feasibility for prioritizing double-bagged swipes. The manufacturer of the microscope at Oak Ridge is capable of building custom filter sets and, if the technique is found feasible, information on the specific optics to be used could be provided to build a tailored filter cube for uranyl fluoride, uranyl nitrate, or other fluorophores of interest. 


\subsection{NOT-RECOMMENDED TECHNOLOGIES}

\subsubsection{Handheld Raman Analyses}

While a point-and-shoot approach to Raman spectroscopy may be feasible using the appropriate wavelength, there remains a high likelihood of encountering a heterogeneous distribution of particulates associated with materials of concern to the IAEA. For this reason, an approach that can ultimately raster scan the entirety of a swipe (such as confocal Raman microspectroscopy) is strongly recommended should this method be chosen for pre-screening. Other specialized techniques may be evaluated in the future, but they are currently far beyond the scope of this study. The results from this work show that point-and-shoot Raman spectroscopy using a 532-nm excitation source is infeasible for prioritization of swipes for destructive analysis.

\subsubsection{ATR Infrared Spectroscopy}

Upon initial testing with bagged cellulose swipes containing cobalt, it became readily apparent that, while the bag material did not pose a spectral interference, the sample had to be compressed significantly for the ATR port to function. This resulted in damage to the bag and the sample with a visible indentation observed. The integrity of the bag would then be put into question. Multiple engineering solutions were attempted to work around this issue, including providing a number of backing materials and weights to provide the required analytical surface. However, none of these efforts resulted in obvious cobalt or polyethylene absorption signals or even a consistent signal from location to location on the sample bags. At this point, we decided to focus additional effort on more promising techniques.

\subsection{OTHER POTENTIAL TECHNIQUES}

\subsubsection{Infrared Micro-Spectroscopy}

While ATR-IR spectroscopy was deemed inadequate for pre-screening purposes, IR micro-spectroscopy may prove to be a very promising method for nondestructive swipe analysis. This vibrational analysis method employs excitation wavelengths that are unlikely to produce fluorescence interference (such as that observed in the point-and-shoot Raman work) and would be amenable to raster scanning an entire swipe surface for macro-scale imaging. Due to the optics utilized, the technique would also be able to reduce or eliminate the interference presented by the bags containing the swipe, thus preserving chain of custody. Such an instrument is not currently available to the team, so any initial studies would involve interfacing with vendors for analysis of surrogate samples to determine feasibility. If deemed promising on surrogate samples, additional funds would be requested to purchase an IR microscope to fully characterize the feasibility of IR microscopy in pre-screening applications. 
A preliminary study, including surrogate sample preparation and sample analysis through potential vendors, would cost approximately $\$ 35,000$. A full-scale study involving instrument purchase would be a substantial financial expansion of the project, likely in the range of $\$ 280,000-\$ 350,000$.

\subsubsection{Nuclear Magnetic Resonance}

Nuclear magnetic resonance (NMR) is a spectroscopic technique that utilizes the different magnetic moments of nuclei in a compound and the different electronic environments surrounding those nuclei to differentiate between molecular species. As an example, ${ }^{1} \mathrm{H},{ }^{19} \mathrm{~F},{ }^{13} \mathrm{C}$, ${ }^{15} \mathrm{~N}$, and ${ }^{235} \mathrm{U}$ all have different magnetic moments and can be distinguished by the NMR method. One interesting point regarding NMR is that it is a quantitative measurement and can therefore be used to assess the amount of material present. However, NMR is traditionally known as a technique that requires a large sample. Over the past decade, many NMR companies have been pushing the limits of sensitivity by increasing the magnetic field with which the system operates and by actively cooling the electronic detection systems to the lowest temperatures $(4 \mathrm{~K})$. Both of these efforts have greatly increased the sensitivity of the instrument. In this effort, samples of varying quantity of materials would be assessed by these new NMR systems to determine their detection limits and find out whether the technique is applicable for pre-screening. The overall cost of this assessment would be approximately $\$ 50,000$. 


\section{REFERENCES}

Begun, G.M., Haire, R.G., Wilmarth, W.R., and Peterson, J.R., 1990, Raman spectra of some actinide dioxides and of $\mathrm{EuF}_{2}$. Journal of the Less-Common Metals, 162, 192-133.

Gantner, E., Steinert, D., and Reinhardt, J., 1985, Raman measurements of tributyl phosphate after adsorption on silver hydrosols. Analytical Chemistry, 58, 1658-1662.

IAEA, 2011, IAEA Safeguards Techniques and Equipment, International Verification Series No. 1 (Rev. 2), International Atomic Energy Agency: Vienna, Austria.

Kuhn, E., Fischer, D., and Ryjinski, M., 2001, Environmental Sampling for IAEA Safeguards: A Five Year Review, IAEA-SM-367/10/01, International Atomic Energy Agency: Vienna, Austria.

Miller, F.A., and Wilkins, C.H., 1952, Infrared spectra and characteristic frequencies of inorganic ions, Analytical Chemistry, 24 (8), 1253-1294.

Pointurier, F., Marie, O., Hubert, A., Fauré, A.L., and Pottin, A.C., 2010, Recent Improvements of Actinides Trace Analysis in Environmental Samples for Nuclear Activities Detection, IAEACN-184/29, International Atomic Energy Agency: Vienna, Austria.

Sarsfield, M.J., Taylor, R.J., Puxley, C., and Steele, H.M., 2012, Raman spectroscopy of plutonium dioxide and related materials, Journal of Nuclear Materials, 427, 333-342.

Shimazdu Corporation, 2015, IRTracer-100 - Applications, http://www.shimadzu.com/an/spectro/ftir/irtracer/irtracer_5.html (accessed 2015-11-01).

Steeb, J.L., Smith, N.A., Lee, D.L., Huckabay, H.A., and Ticknor, B.W., 2015, Technology Recommendations for Pre-screening of IAEA Swipe Samples, Progress Report, ANL/NE-15/5, Argonne National Laboratory: Argonne, Illinois. 


\section{Argonne}

Nuclear Engineering Division

Argonne National Laboratory

9700 South Cass Avenue, Bldg. 205

Argonne, IL 60439

www.anl.gov

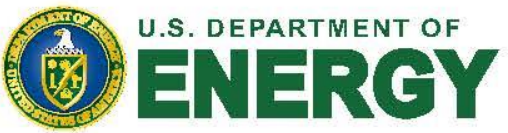

Argonne National Laboratory is a U.S. Department of Energy

laboratory managed by UChicago Argonne, LLC 